\title{
A Delay in Consolidation is Observed in a Heterozygous Conditional BMP2 Deficient Mouse Model of Distraction Osteogenesis
}

\author{
Norine Alam \\ Department of Human Genetics \\ McGill University \\ Montreal, Québec \\ Canada
}

February 2009

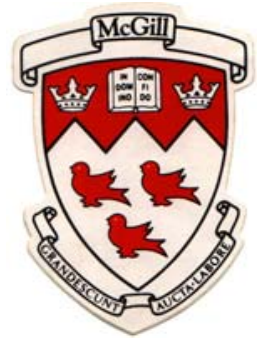

A thesis submitted to McGill University, Faculty of Graduate and Postdoctoral Studies, in partial fulfillment of the requirements of the degree of Masters of Science in Human Genetics

CCopyright Norine Alam, 2009. 
To my loving parents 


\begin{abstract}
Distraction osteogenesis (DO) is a surgical technique used to treat limb length discrepancies, limb deformities, long bone non-unions and bone loss due to trauma, infection or malignancies. In this surgical method a transverse osteotomy is performed and the fractured bone is stabilized using the Ilizarov fixation system. After a short latency period, the two ends of the fractured bone are slowly pulled apart, stimulating new bone formation within the distracted gap. After the distraction is completed, the newly formed bone is allowed to fully consolidate.
\end{abstract}

One of the main limitations of DO is the long consolidation period required for the bone to heal. Different methods have been researched to accelerate the consolidation phase of DO, including the exogenous application of bone morphogenetic proteins (BMPs). BMPs are growth factors that are required in the bone developmental pathway. Although numerous studies have tested pharmacological doses of BMP2 and BMP7 using different animal models of DO, the physiological role of BMPs during DO still remains poorly understood. Hence, in this study we investigated the physiological role of BMP2 in a heterozygous conditional BMP2 knockout model of distraction osteogenesis.

Distraction osteogenesis was performed on the right tibia of forty wildtype BMP2 $2^{f l /+}$ mice and heterozygous BMP2 ${ }^{f l /+}$ cre mice using a miniature version of the Ilizarov fixator. Mice underwent a latency period of 5 days, a distraction period of 12 days (distraction rate of $0.2 \mathrm{~mm}$ every 12 hours) and a consolidation 
period of 34 days. Distracted samples were collected from four time points: 11 days (mid-distraction phase), 17 days (end of distraction phase), 34 days (midconsolidation phase) and 51 days (end of consolidation phase). Samples were studied using $\mu \mathrm{CT}$, Faxitron x-ray, immunohistochemistry, histology, Real Timequantitative PCR and biomechanical testing.

Results from this study showed that reducing BMP2 expression through gene dosage had an effect of delaying the consolidation process in the heterozygous mice. $\mu \mathrm{CT}$ analysis of static histomorphometric parameters revealed a statistically significant decrease in trabecular number and increase in trabecular separation at 51 days in the heterozygous mice. Immunohistochemical studies demonstrated a decrease in the expression of BMP2, BMP7, BMPR1a, ACTR1, ACTR2b at 34 days post-osteotomy, which can account for the poor bone formation patterns observed during the consolidation phase of DO. Consistent with these results, biomechanical testing of 51 day samples revealed a decrease in stiffness and increase in ultimate displacement in the heterozygous mice compared to the wild-type controls.

Therefore, results from this study suggest that BMP2 exerts a physiological role during DO. 


\section{RÉSUMÉ}

L'ostéogenèse par distraction (OD) est une technique chirurgicale utilisée pour traiter des dissymétries des membres et des défauts osseux suite à un traumatisme, une infection ou une maladie. Dans cette méthode, une ostéotomie est faite et l'os fracturé est stabilisé par un fixateur externe de type Ilizarov. Durant la période de distraction, les extrémités de l'os sont tirées lentement l'une de l'autre, ce qui stimule la nouvelle formation d'os dans la zone de distraction. Ensuite, la phase de consolidation permet l'ossification de tissu nouvellement formé.

Le problème principal de l'OD est que la période de consolidation est très longue. De recherches ont été faites afin d'accélérer la phase de consolidation de l'OD tel que l'application des protéines de la morphogenèse osseuse (BMP). Les BMP sont nécessaires pour le développement osseux. Bien que beaucoup d'études ont analysé les effets de doses pharmacologiques de BMP2 et BMP7 en utilisant des modèles animaux de l'OD, le rôle physiologique des BMP est encore inconnu. Donc, pour cette étude nous avons analysé le rôle physiologique de BMP2 durant l'OD chez des souris ayant une déficience en BMP2 localisée dans les membres.

Nous avons soumis le tibia droit de souris contrôle-BMP2 ${ }^{\mathrm{fl} /+}$ et de souris hétérozygotes-BMP2 ${ }^{\mathrm{fl} / / \text { cre }}$ à l'ostéogenèse par distraction en utilisant un fixateur Ilizarov miniaturisé. Les souris ont subi une période de latence de 5 jours, une période de distraction de 12 jours (avec un taux de distraction de $0.2 \mathrm{~mm}$ chaque 12 heures), et une période de consolidation de 34 jours. Les échantillons ont été recueillis à $11,17,34$ et 51 jours, et analysés par $\mu \mathrm{CT}$, rayons $\mathrm{X}$, 
immunohistochimie, histologie, par PCR en temps réel, et par un examen biomécanique.

Les résultats de cette étude ont montré que la diminution de l'expression de BMP2 dans les membres hétérozygotes avait pour effet de ralentir le processus de consolidation. L'analyse des paramètres $\mu \mathrm{CT}$ d'échantillons de 51 jours a révélé une diminution significative dans le nombre de trabécules et une augmentation significative dans la séparation des trabécules dans les souris hétérozygotes. L'analyse par immunohistochimie a démontré une réduction dans l'expression de BMP2, BMP7, BMPR1a, ACTR1, ACTR2b à 34 jours après la chirurgie; ce qui pourrait contribuer à la formation d'os retardée pendant la phase de consolidation de l'OD. L'examen biomécanique des échantillons hétérozygotes à 51 jours a révélé une diminution de la raideur et une augmentation du déplacement ultime.

En conclusion, les résultats de cette étude suggèrent que BMP2 a un rôle physiologique au cours de l'OD. 


\section{ACKNOWLEDGEMENTS}

I would firstly like to thank my supervisors, Dr. René St-Arnaud and Dr. Reggie Hamdy, for giving me the opportunity to complete a Masters' degree under their supervision. I would like to thank you both for your guidance and constant support throughout my project. I will always be very grateful for my graduate years as this period has helped strengthen and prepare myself for the challenges that lie ahead.

I would like to thank, Tasima Haque, for everything, if it weren't for you I would never have been in grad school! I would also like to thank Fares Hamadeh for teaching me and helping me master the surgical method of distraction osteogenesis. I would like to thank the animal technicians, Mia, Louise and Nathalie for assisting me with the mouse surgeries.

Thanks to members of the McGill Bone Centre for $\mu \mathrm{CT}$, Faxitron x-ray and biomechanical testing analysis.

My sincere gratitude to members of Dr. St-Arnaud's lab, thank you all for always helping with my long experiments. I will miss you guys! Mark and Guylaine, thank you for helping with graphics.

I would like to thank my family members: Ama, Aba, Roshni \& Arjun, and Saadat for your undying love and continuous support. I would never have been able to make it this far without you. One love. Allah. 


\section{TABLE OF CONTENTS}

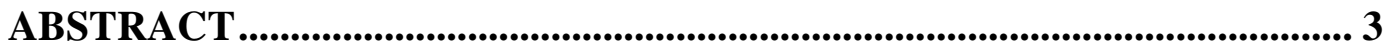

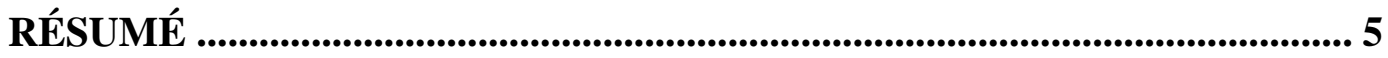

ACKNOWLEDGEMENTS ….................................................................. 7

TABLE OF CONTENTS …................................................................. 8

LIST OF FIGURES ................................................................................................... 10

LIST OF TABLES ................................................................................................... 11

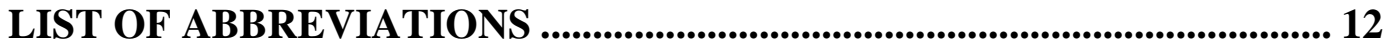

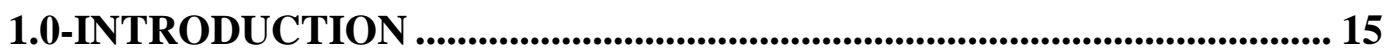

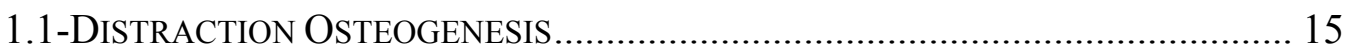

1.1.1-HISTORICAL BACKGROUND.......................................................... 15

1.1.2-PRINCIPLE OF TENSION-STRESS.................................................... 17

1.1.3-PHASES OF DisTRACTION OSTEOGENESIS.......................................... 20

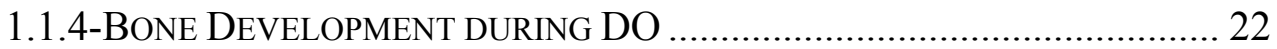

1.1.5-COMPLICATIONS AND DRAWBACKS OF DO …………….................... 27

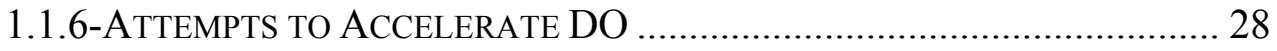

1.1.6.1-Mechanical Stimulation ...................................................... 29

1.1.6.2- Low-Intensity Pulse Ultrasound (LIPUS)............................. 30

1.1.6.3-Transplantation of Bone Marrow Cells (BMCs)..................... 32

1.1.6.4- Transplantation of Osteoblastlike cells .................................. 34

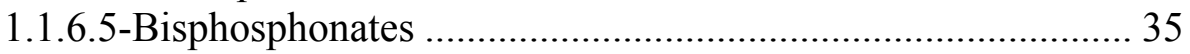

1.1.6.6-Growth Factors.................................................................... 36

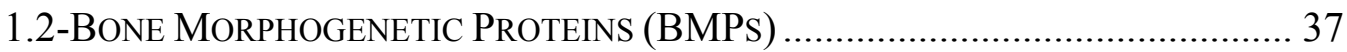

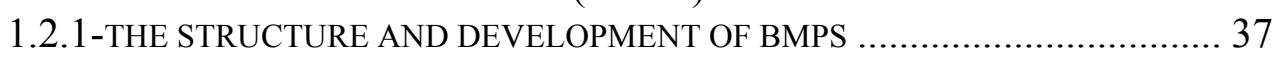

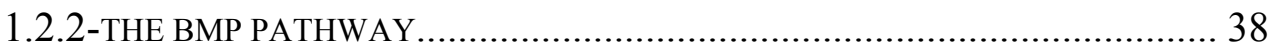

1.2.3-DOWNSTREAM PATHWAYS: ERK-MAPK PATHWAY ………………...... 38

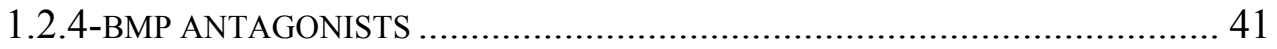

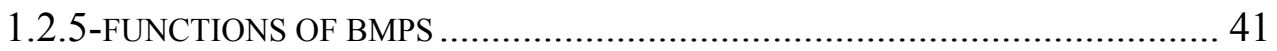

1.2.6-EFFECTS OF BMP ADMINISTRATION DURING DO................................. 42

2.0-OBJECTIVE OF STUDY .............................................................................. 47

3.0-MATERIALS \& METHODS .......................................................................... 48

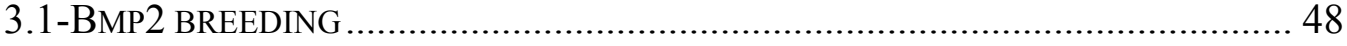

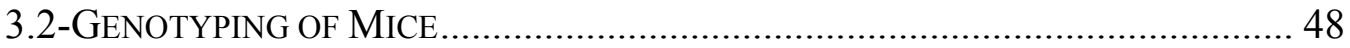

3.2.1-DNA EXTRACTION FROM MOUSE TAILS.............................................. 48

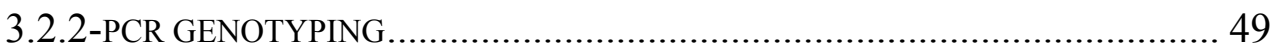

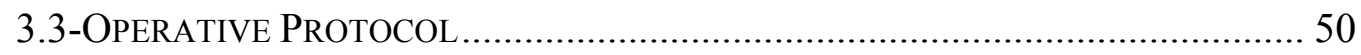

3.4-MICRO-COMPUTED TOMOGRAPHY $(\mu \mathrm{CT})$ \& FAXITRON X-RAY .................. 51

3.5-IMMUNOHISTOCHEMICAL ANALYSIS ....................................................... 52

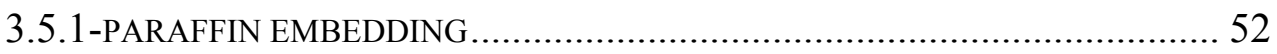

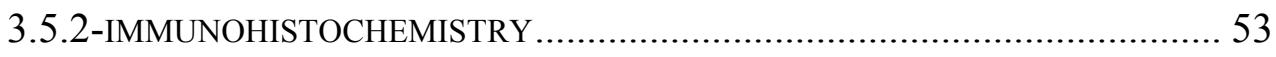

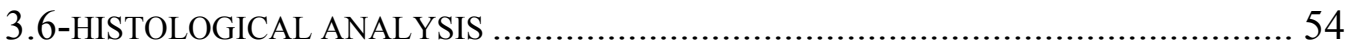




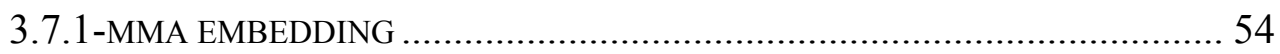

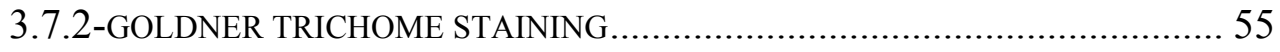

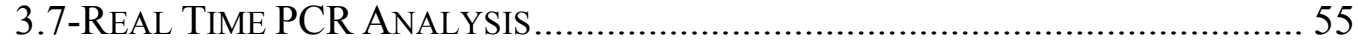

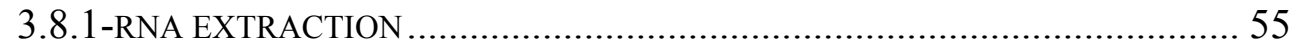

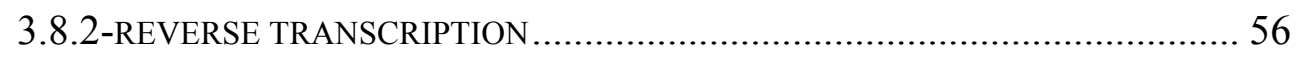

3.7.1-REAL TIME QUANTITATIVE PCR (RT-QPCR)................................... 57

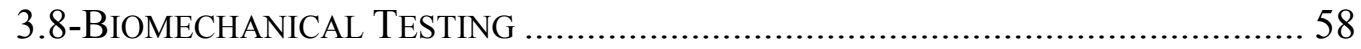

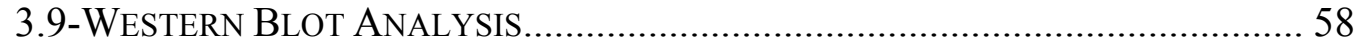

3.9.1-PROTEIN EXTRACTION FROM BONE TISSUE........................................ 58

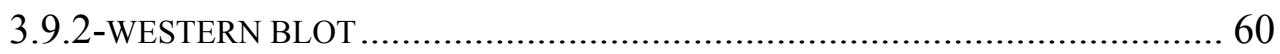

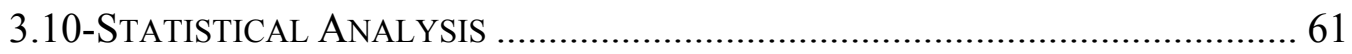

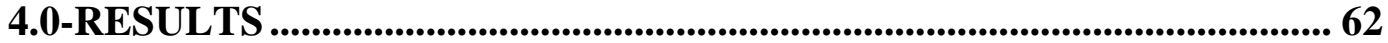

4.1- Surgical Success Rate of Conditional BMP2 Deficient Mice......... 62

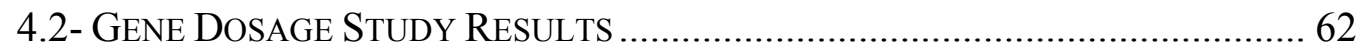

4.3-MicRO-COMPUTED TOMOGRAPHY $(\mu \mathrm{CT})$ \& FAXITRON X-RAY RESULTS..... 65

4.4-IMMUNOHISTOCHEMISTRY RESULTS ..................................................... 70

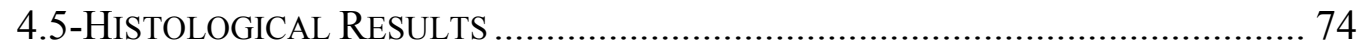

4.6-Real Time Quantitative PCR Results............................................... 79

4.7-BIOMECHANICAL TESTING RESULTS ...................................................... 81

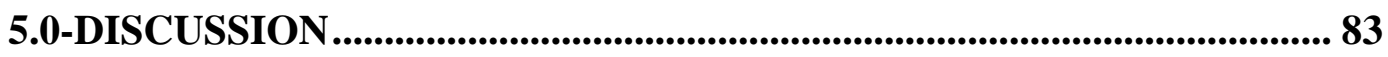

6.0-REFERENCES .............................................................................. 90

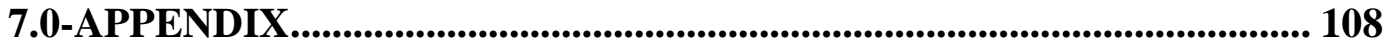

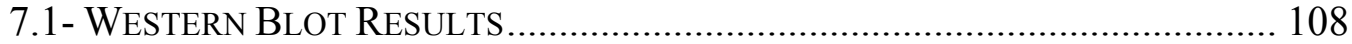

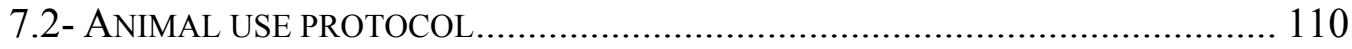

7.3- MOUSE WORKSHOP CERTIFICATES …...................................................... 111 


\section{LIST OF FIGURES}

Figure 1: Distraction osteogenesis on a wild-type mouse tibia.

Figure 2: Phase of distraction osteogenesis.

Figure 3: Endochondral ossification vs. intramembranous ossification.

Figure 4: BMP signaling pathway.

Figure 5: Western blot of BMP signaling in wild-type mouse model of DO.

Figure 6: Undistracted BMP2 deficient mice exhibit a BMP2 gene dosage effect.

Figure 7: Poor bone formation was observed during DO in the heterozygous BMP2 deficient mice.

Figure 8: Static histomorphometric parameters revealed heterozygous BMP2 deficient mice had poor bone healing patterns during the end of consolidation.

Figure 9: Immunohistochemical images of BMP2 expression in heterozygous BMP2 deficient mice.

Figure 10: No mineralized tissue was present in the distracted samples of heterozygous BMP2 ${ }^{f l /+ \text { cre }}$ mice at 17 days post-osteotomy.

Figure 11: At 34 days post-osteotomy, the distracted zone of heterozygous $\mathrm{BMP} 2^{\mathrm{fl} / \mathrm{cre}}$ mice contained no mineralization.

Figure 12: Improper bone healing was observed in distracted BMP2 $f l+c r e$ mice at 51 days post-osteotomy.

Figure 13: Biomechanical testing results of distracted wild-type \& heterozygous BMP2 deficient mice at 51 days post-osteotomy 


\section{LIST OF TABLES}

Table 1: $\mu \mathrm{CT}$ analysis of wild-type \& heterozygous BMP2 deficient mice.

Table 2: Immunolocalization of BMP factors in chondrocytes present in the distracted zone of wild-type and heterozygous BMP2 deficient mice.

Table 3: No difference in the expression of BMP signaling pathway members was detected between wild-type \& heterozygous BMP2 deficient mice. 


\section{LIST OF ABBREVIATIONS}

\begin{tabular}{|c|c|}
\hline$\mu \mathrm{CT}$ & Micro-computed tomography \\
\hline ActR & Activin receptor \\
\hline ATF-4 & Activating transcription factor-4 \\
\hline ALK & Activin receptor-like kinase \\
\hline ALP & Alkaline phosphotase \\
\hline $\mathrm{BMC}$ & Bone marrow cell \\
\hline BMP & Bone morphogenetic protein \\
\hline BMPR & Bone morphogenetic protein receptor \\
\hline BSA & Bovine serum albumin \\
\hline cDNA & Complementary deoxyribonucleic acid \\
\hline co-SMAD & Common-partner mothers against decapentaplegic homolog \\
\hline Colla1 & Collagen type I \\
\hline DEPC & Diethylpyrocarbonate \\
\hline DO & Distraction osteogenesis \\
\hline DTT & Dithiothreitol \\
\hline EDTA & Ethylenediaminetetraacetic acid \\
\hline EGMA & Ethylene glycol monoethyl acetate \\
\hline EGF & Epithelial Growth Factor \\
\hline ERK & Extracellular signal-regulated kinase \\
\hline FGF & Fibroblast growth factor \\
\hline GAPDH & Glyceraldehyde 3-phosphate dehydrogenase \\
\hline HGF & Hepatocyte growth factor \\
\hline IGF & Insulin-like growth factor \\
\hline
\end{tabular}




\begin{tabular}{|c|c|}
\hline I-SMAD & Inhibitory mothers against decapentaplegic homolog \\
\hline LIPUS & Low-intensity pulse ultrasound \\
\hline MAPK & Mitogen-activated protein kinase \\
\hline MMA & Methyl methacrylate \\
\hline mRNA & Messenger ribonucleic acid \\
\hline $\mathrm{NaCl}$ & Sodium chloride \\
\hline $\mathrm{OCN}$ & Osteocalcin \\
\hline OSX & Osterix \\
\hline PBS & Phosphate buffer saline \\
\hline PCR & Polymerase chain reaction \\
\hline PDGF & Platelet-derived growth factor \\
\hline PFA & Paraformaldehyde \\
\hline PRP & Platelet-rich plasma \\
\hline PRX-1 & Paired-related homeobox-1 \\
\hline R-SMAD & $\begin{array}{l}\text { Receptor-regulated mothers against decapentaplegic } \\
\text { homolog }\end{array}$ \\
\hline RT-qPCR & Real Time quantitative polymerase chain reaction \\
\hline rhBMP & Recombinant human bone morphogenetic protein \\
\hline RNA & Ribonucleic acid \\
\hline Runx2 & Runt-related transcription factor 2 \\
\hline SDS & Sodium dodecyl sulfate \\
\hline SMAD & Mothers against decapentaplegic homolog \\
\hline SMURF & Smad ubiqutin regulatory factor \\
\hline Sox9 & Sex determining region Y-box 9 \\
\hline
\end{tabular}


TBS-T

TCA

TGF- $\beta$

TRIS
Tri-phosphate buffer saline-tween

Trichloroacetic acid

Transforming growth factor- $\beta$

Hydroxymethylaminomethane 


\section{0-INTRODUCTION}

\section{1- Distraction Osteogenesis}

Distraction osteogenesis (DO) is a surgical procedure used to treat limb length discrepancies, bone deformities \& non-unions and bone loss resulting from congenital conditions, trauma, infection or osteomyelitis (Ilizarov.1989a,b; Ilizarov. 1990). The process of distraction osteogenesis involves performing a transverse osteotomy at the affected site, fracturing the bone. Post-osteotomy, the fractured bone is kept in position using a stable circular Ilizarov external fixation system. The Ilizarov fixator is a cylindrical apparatus containing two metallic rings (each ring contains two wires that are transfixed to the bone) that are connected to each other by three long threaded rods (Fig. 1). During distraction, the two ends of the fractured bone are gradually pulled apart at a fixed rate of 1.0 $\mathrm{mm} /$ day in humans for a specified period of time. Using the host's bone regenerative abilities, distracting the two fractured ends stimulates newly remodeled bone to form within the lengthened gap. Following distraction, the newly formed bone is allowed to heal until full consolidation.

\subsection{1-Historical Background}

In 1951, Dr. Gavriil Abramovitch Ilizarov developed the surgical technique of distraction osteogenesis. Ilizarov first sparked his idea of DO when a patient mistakenly started turning the rods of his circular external fixator. Ilizarov noticed that progressively, new bone had developed within the fractured gap. Intrigued by this biological finding and its potential use in clinical treatment, Ilizarov began researching the technique using animal models. In 1980, Ilizarov 


\section{A}
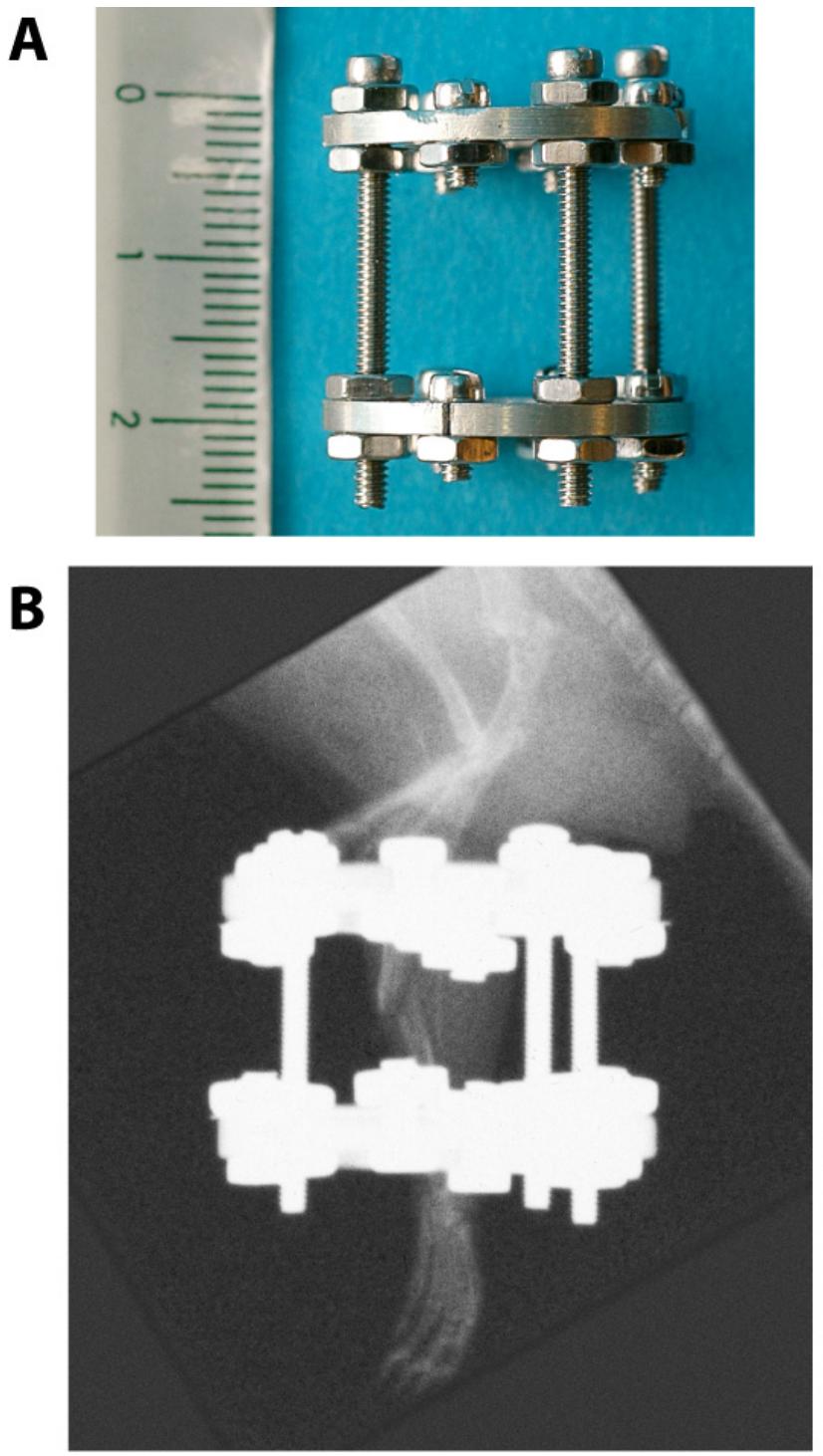

Figure 1 Distraction Osteogenesis on a Wild-Type Mouse Tibia.

(A) A miniature version of the llizarov external fixator is used on the mouse model of DO. (B) An X-ray image of a mouse model of DO reveals an osteotomy was made on the right tibia of the mouse and stabilized using an llizarov fixation system. Post-osteotomy, the two ends of the fractured bone were pulled apart at a fixed rate of $0.5 \mathrm{~mm}$ every 12 hours, stimulating bone regeneration to occur within the distracted gap. 
successfully treated Carlo Mauri's, an Italian explorer, case of pseudoarthrosis using DO. Mauri was very impressed with the results of his surgery and he set out with Ilizarov to introduce this novel method of fracture treatment to the orthopedic community. By the mid-1970s and 80 s, DO had gained public recognition and was commonly practiced around Western Europe and North America (Ilizarov. 1990).

\subsection{2-Principle of Tension-Stress}

Ilizarov and colleagues derived the Principle of Tension-Stress to explain the bone regenerative mechanism used during DO. The Principle of TensionStress states that the slow and steady traction of a living tissue metabolically activates biosynthetic and proliferative pathways involved in bone regeneration within the distracted zone (Ilizarov.1989a,b; Ilizarov. 1990). According to this theory, the quality of bone that develops within the distracted zone depends on several factors: the stability of the external fixation system, the amount of damage induced to environment of the distracted zone, the rate of distraction and the frequency of distraction.

A stable external fixation system used during DO allows for rapid consolidation of the fractured gap with minimal formation of fibrocartilaginous tissue. Furthermore, a stable Ilizarov device ensures that there is proper alignment of the fractured bone at the osteotomy site and decreases the risk of damaging the surrounding periosteal tissue that may be induced by movement of osseous fragments. An unstable fixation system that contains unsteady frames 
with loosely attached wires to the bone may result in a delay in consolidation and the formation of fibrous nonunion (Ilizarov.1989a,b; Ilizarov. 1990).

Minimizing the damage to the surrounding environment of the distracted zone (i.e. bone marrow, periosteal tissues and blood vessels) is necessary for maintaining proper bone healing of the bony bridge. Alongside with a stable fixation system, the type of osteotomy performed during DO also affects the surrounding soft tissue and angiogenic system. In many cases, surgeons may prefer a closed osteoclasis over an open osteotomy technique because it is a less invasive technique. The closed osteoclasis technique relies on the use of a curved wire to break the cortex of the bone without making an open incision on site, minimizing damage to the bone marrow and soft tissue present at the osteotomy site. Contrarily, an open osteotomy involves making an open incision to break the bone at the affected site, leaving the risk for infection (Ilizarov.1989a,b; Ilizarov. 1990).

Ilizarov tested different rates and frequencies of distraction on a canine model of DO to determine the optimal conditions for bone regeneration within the distracted zone. For the first set of experiments, Ilizarov and colleagues tried distracting canine tibiae at the minimal rate of $0.5 \mathrm{~mm} /$ day using two conditions: 1) distraction at a frequency of $0.125 \mathrm{~mm}$ every 6 hours and 2) distracting the tibiae with an autodistractor at a frequency of $0.085 \mathrm{~mm}$ every 24 minutes. The results showed that the tibial samples that were subjected to condition 1 developed some osteogenic activity \& premature ossification, however, the 
osseous fragments remained relatively unconsolidated. Tibial samples that were distracted using the autodistractor in condition 2 demonstrated better consolidation patterns than condition 1 . For the second set of experiments, a distraction rate of $1.0 \mathrm{~mm} /$ day was tested under three conditions: 3 ) distraction at a frequency of $1.0 \mathrm{~mm}$ every 24 hours, 4) distraction at a frequency of $0.25 \mathrm{~mm}$ every 6 hours and 5) distraction using an autodistractor that lengthens the canine bone $0.017 \mathrm{~mm}$ every 24 minutes. The results showed that tibia exposed to condition 3 developed very low density bone within the distracted gap 28 days post-osteotomy. Distracted tibial samples that were subjected to condition 4 displayed partial consolidation of the fractured bones, containing dense bone that had partially remodeled into new cortical bone 60 days post-osteotomy. Bones subjected to condition 5 produced the strongest bone at 60 days post-osteotomy: the distracted zone contained newly remodeled cortical and trabecular bone that resembled the host's original bone. In the last set of experiments, the distracted tibial samples that underwent a maximal rate of $2.0 \mathrm{~mm} /$ day developed a callus that was largely composed of dense fibrous tissue with very little osteogenic activity. Further histological analysis was conducted on distracted canine tibial sections testing all three rates. Sections were measured for succinyl dehydrogenase (a marker for osteogenic activity), alkaline phosphotase (ALP-a marker for matrix mineralization) and ATPase (a marker for the rate of osteoblast formation in primary bone matrix). Histological analysis revealed that sections from condition 5, using an autodistractor to distract samples at rate of $1.0 \mathrm{~mm} /$ day and a frequency of $0.017 \mathrm{~mm}$ every 24 minutes, exhibited the most osteogenic activity within the distracted gap; with the highest levels of succinyl 
dehydrogenase, ALP and ATPase activity. Based on these results, Ilizarov concluded a distraction at a rate of $1.0 \mathrm{~mm}$ /day with increased frequency of turns during distraction produced the highest levels of osteogenic activity with a short consolidation period (Ilizarov.1989a,b; Ilizarov. 1990).

Thus, in accordance to the Principle of Tension and Stress, optimal conditions for the proper consolidation of the distracted zone during DO include containing a stable external fixation system with a strong frame and wires that are

tightly secured to bone, minimizing disturbances to the surrounding soft periosteal tissues, bone marrow and blood vessels around the zone of distraction and using a distraction rate of $1.0 \mathrm{~mm} /$ day with increased frequency of turns.

\subsection{3-Phases of Distraction Osteogenesis}

Distraction osteogenesis is divided into three major phases: the latency phase, the distraction phase and the consolidation phase (Fig. 2). Following the first day post-osteotomy, the latency phase lasts a period of five to seven days when there is no distraction and callus formation is initiated. A latency period longer than five days can lead to premature ossification of the distracted zone. After the latency period, the second phase of DO is the distraction or lengthening phase. During the elongation period, the two fractured ends are gradually distracted at a rate of $1.0 \mathrm{~mm} /$ day (minimum frequency of four increments of 0.25 mm every 6 hours) till the desired length is reached. Distraction in multiple steps instead of once per day develops strong bone within the distracted zone without the formation of a cartilaginous intermediate that may 


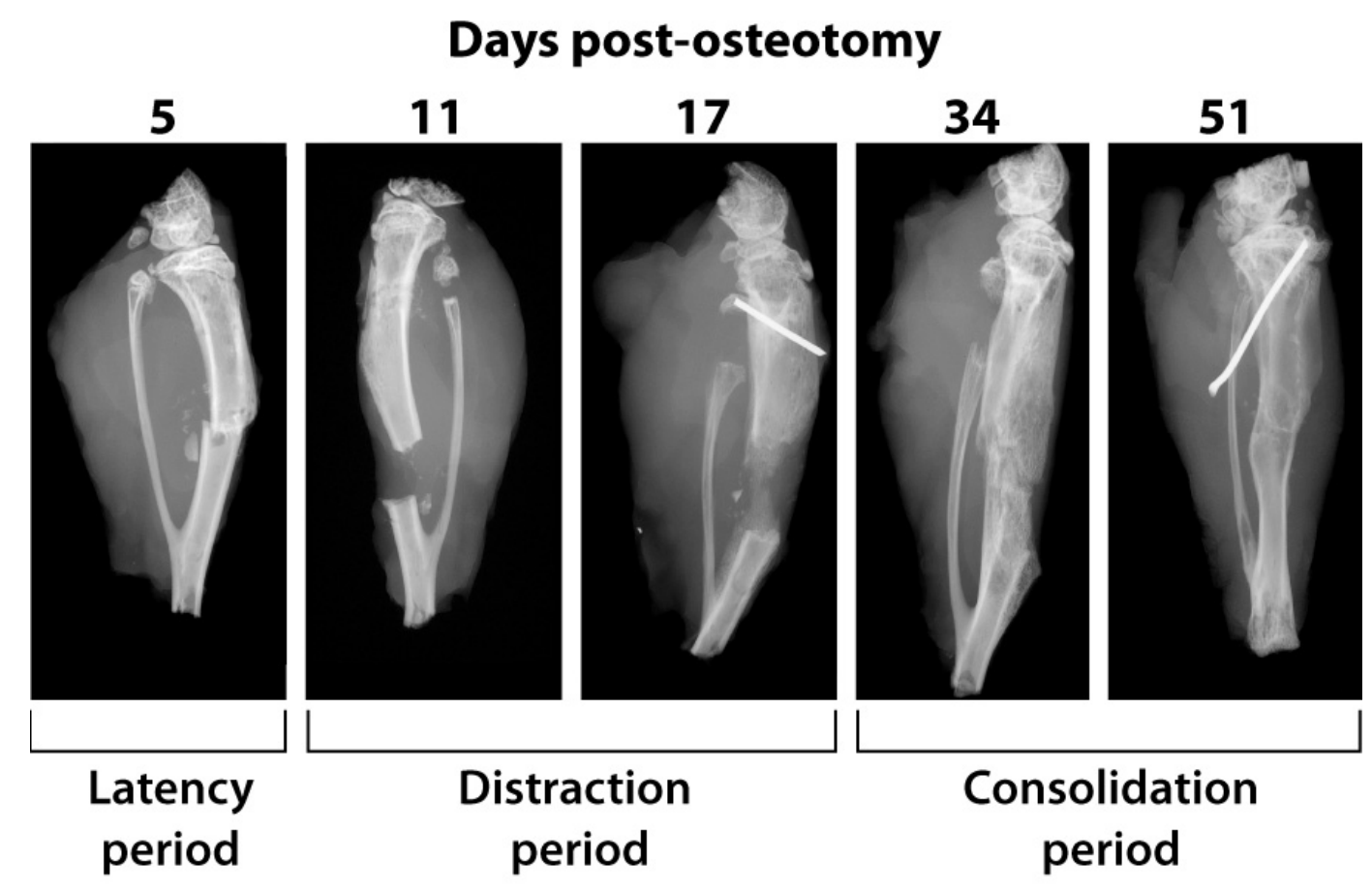

Figure 2 Phases of Distraction Osteogenesis.

Radiological images of a wild-type mouse model of DO demonstrate the process of bone regeneration within the distracted gap. Distracted tibial samples were collected from the different phases of DO. Following distraction, the $x$-rays revealed the distracted zone was gradually filled with newly mineralized bone. 
contribute to delayed consolidation. The act of distracting the two bony fragments enhances angiogenic activity, activating intracellular pathways that recruit cells to the fractured site. As distraction progresses, fibroblast-like cells grow parallel to the direction of the tension-stress vector in the lengthened gap. The fibroblast-like cells produce collagen fibers that condense into bundles throughout the callus. In addition, osteoblasts deposit osteoid along the collagen fibers, beginning the consolidation phase of DO. During the consolidation phase, the fixator is left in place until the bone acquires enough strength to withstand mechanical stress of everyday activities. This period can last for months depending on the distraction length, since the patient is required to keep on the Ilizarov device on for a month for every centimeter distracted. During consolidation, the process of bone remodeling continues developing trabecular and cortical bone within the callus. The remodeled bone within the distracted gap usually contains the same properties as the host's original bone (Ilizarov.1989a,b; Ilizarov. 1990).

\subsection{4-Bone Development during DO}

There are two types of ossification that are essential for osteogenesis: endochondral and intramembranous ossification (Fig. 3). These two bone developmental mechanisms are used to produce the long and flat bones of the body. The difference between these two processes of ossification is that intramembranous ossification involves a one-stage process where mesenchymal cell-derived osteoblasts produce bone, whereas endochondral ossification 
involves a two-step mechanism that uses a cartilaginous intermediate to develop new bone (Ducy et al., 1998).

Both methods of ossification are initiated by mesenchymal stem cell condensation. The condensed mesenchymal cells that take part in intramembranous ossification develop into preosteoblast cells (Vaes et al., 2006). These preosteoblast cells further differentiate into mature osteoblasts to take part in the bone remodeling process, forming woven bone (Tsiridis et al., 2007). Contrarily, the multistage process of endochondral ossification is initiated with mesenchymal condensation and the production of type II collagen. Mesenchymal cell-derived chondrocytes undergo proliferation and perichondrial cells start expressing type I collagen (Kosher et al., 1986). The type II collagen-expressing, proliferating chondrocytes form a cartilaginous template. Eventually, the chondrocytes stop proliferating and become pre-hypertrophic. The prehypertrophic chondrocytes mature into hypertrophic chondrocytes that express type $\mathrm{X}$ collagen and participate in matrix mineralization. Following maturation, the hypertrophic chondrocytes undergo cell death by apoptosis (Provot et al., 2005). Periosteal-derived osteoblasts and newly formed blood vessels invade the cartilaginous template for trabecular bone formation eventually forming the primary spongiosa (Hartmann. 2007). With continual bone remodeling by osteoblasts and osteoclasts, the center of the primary spongiosa is split into two epiphyseal growth plates that are pushed apart in opposite directions (Provot et al., 2005). 
A

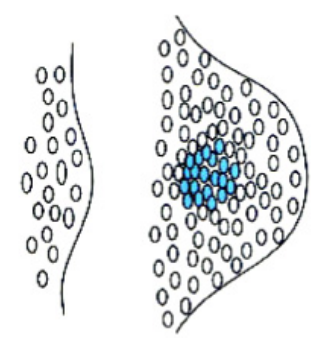

Limb bud Mesenchymal condensation

\section{Endochondral Ossification}

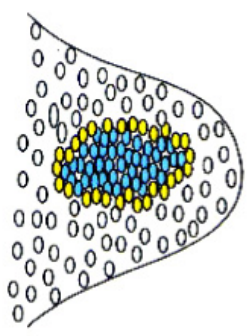

Chondrogenesis Chondrogenesis

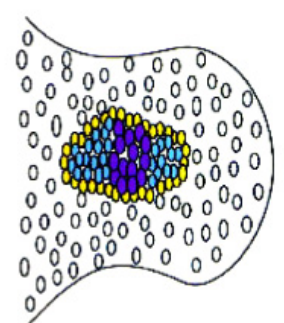

Hypertrophic differentiation

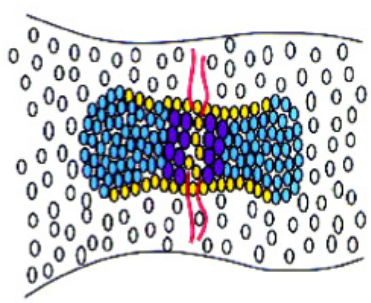

Vascular invasion Periosteum formation Osteoprogenitor cell

B Intramembranous Ossification

Mesenchymal
Condensation
Proliferation Osteoprogenitor cell
Differentiation
$\square$ Osteoblast

\section{Figure 3 Endochondral Ossification vs. Intramembranous Ossification}

There are two types of ossification involved in bone repair: (A) endochondral and (B) intramembranous ossification. These two bone developmental mechanisms are used to produce long and flat bones in the body. Both methods of ossification commence with mesenchymal condensation that eventually produces mineralized bone. Intramembranous ossification involves a one-stage process where mesenchymal cell-derived osteoblasts produce bone whereas endochondral ossification involves a two-step mechanism that uses a cartilaginous intermediate to develop long bones. (Figure adapted from Ornitz et al., 2002) 
Studies analyzing a homozygous Core binding factor $\alpha 1\left(\mathrm{Cbfa}^{-/-}\right)$

knockout mouse model showed that these mice lacked complete bone formation and were compromised of both endochondral and intramembranous ossification (Otto et al., 1997). Cbfal also known as Runt-related transcription factor 2 (Runx2) is a transcriptional factor that is required for osteoblast differentiation (Amir et al., 2007). The $\mathrm{Cbfa}^{-/-}$mice died shortly after birth due to respiratory failure and incomplete formation of the rib cage. Characteristic properties of the $\mathrm{Cbfa}^{-/-}$mice included small stature, lack of mineralization in the skull, mandible, humerus, femur and clavicle, lack of osteoblast differentiation and bone marrow vascularization. Thus, this study demonstrates the importance of these two forms of ossification in bone development (Komori et al., 1997; Otto et al., 1997).

The types of ossification used during DO have been extensively studied. Kojimoto and colleagues completed DO on young Japanese rabbits, stabilized by a unilateral dynamic fixator. These researchers proposed that endochondral ossification was the main bone development process during DO as they only detected the presence of elongated cartilaginous cells and hypertrophic chondrocytes in the callus via histology (Kojimoto et al., 1988). Contrarily, Delloye and colleagues performed DO on adult mongrel dogs using a circular external fixation system. Histological analysis of the distracted canine samples revealed that intramembranous ossification was used to form bone within the distracted gap (Delloye et al., 1990). Similarly, Arnonson and colleagues performed DO on a canine model using two types of fixators, the Ilizarov fixator and the Wagner fixator, and also noticed that intramembranous ossification was 
the only mechanism used for bone formation during DO (Arnonson et al., 1989). In contrast, Rauch and colleagues performed DO on New Zealand rabbits. The osteotomy was completed on the right tibia of the rabbits and stabilized using Orthofix uniplanar fixators. Results indicated that both types of ossification were present in this rabbit model of DO (Rauch et al., 2000).

A group of Japanese researchers detected the presence of three types of ossification used within a rat model of DO: endochondral, intramembranous and transochondroid ossification. Distraction osteogenesis was performed on adult rats, in which bony fragments were supported by a monolaternal external fixator. Histological findings showed the formation of a fibrocartilaginous-based callus that became hypertrophic during early distraction, indicating endochondral ossification was used during this time point of DO. By 10 to 20 days of distraction, histological images revealed the presence of preosteoblasts, osteoblasts and fibroblast-like cells within the cartilaginous callus. Eventually, the cartilaginous callus was resorbed and replaced with new bone, demonstrating that intramembranous ossification was used during the late distraction phase of DO. In between these two phases of bone development, transchondroid ossification was observed during the mid-distraction phase of DO. During transchondroid bone formation, chondrocyte-like cells produced chondroid bone, an intermediate type of tissue that contained properties of both cartilage and bone. The chondroid matrix resembled bone matrix more than a cartilaginous matrix. Furthermore, round chondrocyte-like cells and smaller osteocyte-like cells were present in the histological sections of transchondroid bone. In-situ hybridization 
further confirmed the types of ossification present during each phase of distraction (Yasui et al., 1997).

Based on the Principle of Tension and Stress, Ilizarov observed that type of bone formation that occurred within a distracted gap depends on the stability of the external fixation system. A stable fixation system ensures that the surrounding bone marrow and periosteal tissues around the fracture site are intact, allowing bone regeneration to occur without the development of cartilaginous intermediate. Thus, Ilizarov concluded that intramembranous ossification is the main method of bone development used within a healthy callus of DO (Ilizarov.1989a,b; Ilizarov. 1990). Contrarily, a cartilaginous callus may form within the distracted site via endochondral ossification when there is an unstable fixation system. A cartilaginous callus is usually formed to stabilize and support the fractured segments within the distracted gap (Zhu et al., 1999).

\subsection{5-Complications and Drawbacks of DO}

There are many complications that can arise during surgery, such as the multiple pin insertion at one site can reduce joint mobility and pin insertion through a nerve may result in paralysis of a patient (although such cases are fairly uncommon). Other complications include pin insertion through a vein or artery that may cause vascular damage contributing to hypertension or edema, pin site infections and an incomplete osteotomy preventing the distraction of the fractured segments. Post-consolidation, there may be a possibility that the bone can 
refracture in the distracted site or a different site during the removal of the external fixator (Paley. 1990).

The main drawback associated with DO is the long period of time patients are required to keep on the external fixation system on the affected site (Paley. 1990). For every centimeter the bone is lengthened, the external fixator has to been kept on for one month (i.e. if a patient requires ten centimeters of lengthening, the fixator must kept on for ten months). This drawback can cause financial and psychological problems for the patient and also lead to problems with patient compliance. Thus, researchers are studying methods to accelerate the consolidation phase of DO.

\subsection{6-Attempts to Accelerate DO}

Many studies have been conducted using animal models to analyze the effects of physical and molecular methods that can potentially accelerate the consolidation phase of DO (Paley. 1990). Physical methods have included the use of mechanical stimulation (Greenwald et al., 2000; Kim et al., 2006) and the application of low-intensity pulse ultrasound (LIPUS) (Malizos et al., 2006; Sakurakichi et al., 2004; Eberson et al., 2003; Shimazaki et al., 2000; Claes et al., 2005). Whereas, biological methods have included the transplantation of bone marrow (Kitoh et al., 2007) and osteoblastlike cells into the fracture site (Tsubota et al., 1999; Takamine et al., 2002), the local injection of bisphosphonates (Riggs et al., 2005; Takahashi et al., 2006), and peptide growth factors (Yeung et al., 2001). 


\subsubsection{1-Mechanical Stimulation}

There have been few attempts using mechanical stimulation, such as compressive stimulation, to increase the consolidation phase of DO. The application of compressive stimulation during the distraction phase of mandibular DO demonstrated no significant changes in bone regeneration (Greenwald et al., 2000). Kim et al. studied the effects of compressive stimulation during early consolidation in a rat model of mandibular DO. DO was performed on the mandible of rats followed by a 3 day latency period, a 4 day distraction period (a distraction rate of $0.25 \mathrm{~mm} /$ day twice daily) and a 7 day consolidation period. A compressive force was applied in the direction opposite to distraction at the compression rate of $0.25 \mathrm{~mm} /$ day twice daily for the first four days of consolidation. Therefore, after a total of $4.0 \mathrm{~mm}$ of distraction and $2.0 \mathrm{~mm}$ of compression, the total distraction length was $2.0 \mathrm{~mm}$. Controls were subjected to the same conditions of distraction in the absence of compression. Histological and radiological data demonstrated the presence of a softer callus that had primarily developed via intramembranous ossification in the experimental rat groups compared to the control group during early consolidation. By late consolidation, the compressive force helped decrease the size of the distracted gap, forming a thicker volume compact bone regenerate. Thus, the use of compressive stimulation during the consolidation phase of mandibular DO possibly contributed to the formation of more mature and dense bone by accelerating the differentiation of osteoprogenitor cells to osteogenic cells (Kim et al., 2006). 


\subsubsection{2- Low-Intensity Pulse Ultrasound (LIPUS)}

Low-intensity pulsed ultrasound or (LIPUS) has also been studied for the acceleration of bone healing during DO. LIPUS is a form of mechanical energy that travels to the site of bone repair as pressure waves. At the fracture site, LIPUS enhances the process of angiogenesis, facilitating the exchange of nutrients and waste removal among cells and stimulating the differentiation and proliferation of fibroblasts, chondroblasts and osteoblasts. However, the exact mechanism of LIPUS interaction with the surrounding soft tissue environment of the fracture site still remains poorly understood (Malizos et al., 2006).

Sakurakichi and colleagues studied the application of LIPUS during the distraction phase of DO. DO was performed on the right tibia of white Japanese rabbits using unilateral external fixators ( 7 day latency period, 7 day distraction period using a distraction rate of $1.5 \mathrm{~mm} /$ day and 7 day consolidation period). LIPUS was applied to the fracture site of rabbits using an ultrasound transducer at $200 \mu$ s burst of $1.5 \mathrm{MHz}$ sine waves at a frequency of $1.0 \mathrm{kHz}$ for 20 minutes postdistraction each day (the same conditions are used in humans). The data showed that application of LIPUS during the distraction phase of DO resulted in early bone mineralization with high trabecular bone formation and increased mechanical strength of the distracted rabbit tibia (Sakurakichi et al., 2004). Similar results were observed in another rat model when LIPUS was applied during the consolidation phase of DO. LIPUS-treated rats that underwent 
unilateral femoral lengthening exhibited early bone healing, increased bone volume and trabecular bone formation (Eberson et al., 2003).

Shimazaki's group also studied the effects of LIPUS application during the consolidation period of DO. DO was performed on the right tibia of white Japanese rabbits that were stabilized by unilaternal fixators. These rabbits underwent a 7 day latency period, 10 day distraction period using a distraction rate of $0.5 \mathrm{~mm}$ every 12 hours and a 21 day consolidation period. LIPUS was applied to the distracted site of rabbits using conditions used to treat humans. Xrays and mechanical testing showed that LIPUS-treated rabbits contained an increase in bone mineral density and hard callus formation at the distracted site compared to the LIPUS-untreated controls (Shimazaki et al., 2000). Claes and colleagues also analyzed the outcomes of LIPUS stimulation on a sheep model of DO. DO was performed on the metatarsus of sheep using a custom-made fixation system. The sheep underwent 4 days of latency, 16 days of distraction using a distraction rate of $0.5 \mathrm{~mm}$ every 12 hours and a 64 day consolidation period. The sheep were stimulated with LIPUS for 20 minutes each day starting the first day of consolidation. Results demonstrated a greater axial stiffness and early callus formation in the LIPUS-treated sheep. In addition, a 32\% increase in bone formation was observed in the LIPUS-treated sheep compared to the controls that was predominantly formed via endochondral ossification. This process of callus development in the LIPUS-treated sheep is quite different from the LIPUSuntreated controls that primarily form bone via intramembranous bone formation. 
Thus, LIPUS treatment may enhance endochondral bone formation within the distracted gap (Claes et al., 2005).

\subsubsection{3-Transplantation of Bone Marrow Cells (BMCs)}

Some of the recent advances in tissue engineering, such as the transplantation of bone marrow cells (BMCs), have been studied in animal models to shorten the consolidation period of DO. The transplantation of multipotent BMCs during DO that develop into osteogenic progenitors may enhance bone formation within the fracture site. The advantages of BMC transplantation include the easy isolation of these cells from bone marrow sections and it is a safe treatment with relatively few side effects (Kitoh et al., 2004). Although there are many advantages of using BMC transplantation, researchers have to ensure BMCs are properly delivered to the distracted site for optimal BMC function. Thus, the choice of osteoinductive factors and type of scaffold are important for BMC transplantation during DO. Kitoh and colleagues discovered that the combination of culture expanded BMCs in platelet-rich plasma (PRP) stimulated bone regeneration in patients that had undergone tibial or femoral lengthening. PRP supplied osteoinductive factors, such as platelet-derived growth factor (PDGF), insulin-like growth factor-1(IGF-1) and transforming growth factors (TGF-ßss) that are necessary for bone regeneration. Furthermore, the use of a biodegradable scaffold helped prevent infection and inflammation of the fracture site (Kitoh et al., 2007). 
In Kitoh's study, patients had undergone tibial or femoral lengthening stabilized with a monolateral fixator. Patients were allowed to rest for a 7 to 14 day latency period, after which a distraction rate of $0.5 \mathrm{~mm}$ every 12 hours was applied to patients. BMCs were collected from the iliac crest and grown in culture in the presence of osteogenic supplements. The BMCs were dissolved in venous blood derived- PRP. Upon the injected delivery of BMC-PRP using a bovine collagen scaffold to the distracted site 21 days post-surgery, a mixture of calcium and thrombin was also injected into the fracture site to help clot formation. Assessment of bone regeneration within the lengthened zones was a difficult process as it because it was affected by many factors such as the age of the patient, the required distracted length and the time required for complete consolidation. Thus, a standardized healing index was measured for each patient. This healing index was calculated by the division of the time required for complete consolidation by the total distracted length observed by x-ray analysis. BMC-PRP-treated patients had a smaller healing index than untreated patients, demonstrating a decrease in the consolidation time for DO. Furthermore, a delay in consolidation was observed in $45 \%$ of untreated BMC-PRP patients compared to the BMC-PRP-treated patients that exhibited normal bone healing patterns. Thus, the combination of BMC-PRP transplantation in the distracted site of patients can promote vascular invasion of the fractured zone, accelerating the bone regenerative process during DO (Kitoh et al., 2007). 


\subsubsection{4- Transplantation of Osteoblastlike cells}

Similar to the transplantation of BMCs, periosteum-derived osteoblastlike cells were also used to stimulate bone regeneration during DO. Tsubota and colleagues studied the effects of osteoblastlike cell transplantation in a rabbit model of DO. Tibial lengthening was performed on white Japanese rabbits stabilized by a hemilateral external fixator ( 7 day latency period, 20 day distraction period with a distraction rate of $1 \mathrm{~mm} /$ day and sacrifices were made every 2 weeks during consolidation). Rabbits were divided into three groups: group 1- a control group that underwent distraction without the transplantation of osteoblastlike cells, group 2- a control group of rabbits that were only injected with physiological saline and group 3-test group of rabbits that were injected with periosteum-derived osteoblastlike cells dissolved in physiogical saline. Results showed that group 3 rabbits contained larger and stronger callus formation than the controls as measured by a high transaxial area ratio and three point-bending analysis. The transaxial area ratio was calculated by dividing of the area of distraction by half of the combined distal and proximal diaphyseal areas. Furthermore, the bone mineral density of group 3 was $21 \%$ significantly higher than that of group 1 controls and $42 \%$ higher than group 2 controls. Group 3 rabbits also displayed a significant increase in percent bone mineral density by 27 $\%$ two weeks into consolidation and by $20 \%$ four weeks into consolidation (Tsubota et al., 1999).

In another study, bone marrow-derived osteoblastlike cells were delivered using a collagen-based scaffold in a rat model of DO. DO was 
performed on the left femur of rats and stabilized using a unilateral fixator. Postsurgery, rats were subjected to a 7 day latency period and a 10 day distraction period with a distraction rate of $0.25 \mathrm{~mm}$ every 12 hours. Bone marrow-derived osteoblastlike cells were injected into the distracted zone and rats were sacrificed every two weeks post-transplantation. Controls were injected with either physiological saline, collagen gel or bone marrow derived osteoblastlike cells. Similar to Tsubota's results, the rats that were treated with bone marrow-derived osteoblastlike cells contained larger callus formation compared to the controls. The group of rats that were treated with bone marrow-derived osteoblastlike cells also contained an increase in fracture strength two, four and six weeks posttransplantation as determined by three-point bending analysis. Therefore, both studies demonstrated that the transplantation of osteoblastlike cells enhanced bone formation in the rabbit and rat models of DO. It is possible that the transplantation of the osteoblastlike cells population into the distracted zone increased the number of osteogenic cells and recruited osteoinductive factors to the fracture site that are necessary for bone regeneration, that may account for the large callus formation (Takamine et al., 2002).

\subsubsection{5-Bisphosphonates}

Many of the previously mentioned methods for decreasing the consolidation phase of DO have only focused on enhancing the anabolic effects of bone remodeling. Contrarily, few attempts have been performed to modulate the second component of the bone turnover process: decreasing catabolic activity during DO in order to accelerate bone regeneration within the lengthened gap. 
The use of nitrogen-containing bisphosphonates has shown to increase bone volume during DO. Bisphosphonates are anti-catabolic agents that are used to treat high bone turnover diseases such as osteoporosis (Riggs et al., 2005).

Takahashi and colleagues studied the effects of administering nitrogen-containing bisphosphonates on a rabbit model of DO. Rabbits underwent tibial lengthening with a 5 day latency period, 21 day distraction period (distraction rate of $0.35 \mathrm{~mm}$ every 12 hours) and a consolidation phase of four weeks. Rabbits were injected with $0.4 \mathrm{mg} / \mathrm{kg}$ of nitrogen-containing bisphosphonates for a period of 6 weeks post-osteotomy. Controls were injected with vehicle only. Results showed that the bisphosphonate-treated rabbits contained new bone with greater mechanical strength in the osteopenic zones including 5.6x greater bone volume and 3.3x greater mechanical resistance than the controls. Newly formed bone within the distracted site usually has high bone turnover activity and contains areas of high resorption known as osteopenic zones. Upon the administration of bisphosphonates to rabbits, there was a decrease in osteoclast parameters within the osteopenic zones, indicating a decrease in catabolic activity increased the rate of bone formation during DO (Takahashi et al., 2006).

\subsubsection{6-Growth Factors}

The use of different growth factors may potentially be the most resourceful technique for accelerated bone healing during DO. Different growth factors have been analyzed in fracture healing studies including Transforming growth factor $ß$ (TGF- $ß$ ), Platelet-derived growth factor (PDGF), Insulin-like growth factors (IGF), Fibroblast growth factor (FGF) and Bone morphogenetic 
proteins (BMP) (Yeung et al., 2001). However, BMPs have the strongest osteoinductive properties and have generated substantial interest within orthopedic community for its potential in stimulating bone regeneration during DO.

\section{2-Bone Morphogenetic Proteins (BMPs)}

Bone morphogenetic proteins (BMPs) were first identified by Dr. Marshall Urist in 1965 when he noticed at implantation of demineralized bone matrix in different sites of a rodent model induced ectopic bone formation (Urist, 1965). Twenty BMPs have been identified to date and except for BMP1, all BMPs are a part of the transforming growth factor $\beta$ (TGF- $\beta$ ) superfamily (Xiao et. al., 2007).

\subsection{1-The Structure and Development of BMPs}

Members of the BMP family are synthesized as a large inactive precursor protein that consists of a signal peptide, a pro-domain and a mature peptide (Kirker-Head, 2000). The mature peptide encodes for the functional properties of BMP and is characterized by seven conserved cysteine residues. Upon secretion from the cell, BMP is cleaved at an RXXR consensus sequence, releasing the carboxyl-terminal mature peptide (Rosen. 2006). BMP is activated as the mature peptide undergoes glycosylation and dimerization (Xiao et al., 2007). An active BMP exists as a disulfide-linked homodimer of two identical BMP members or as a more potent disulfide-linked heterodimer of two different BMPs (Kirker-Head. 2000), such as BMP4/7 or BMP 2/7 (Tsiridis et al., 2007). 


\subsection{2-The BMP Pathway}

BMPs interact with two types of serine/threonine kinase receptors: BMPRI (i.e. activin receptor-like kinase-ALK2, ALK3 \& ALK6) and BMPRII (i.e.TALK, activin receptor -ActR2 \& ActR2b) (Rosen. 2006). The BMP cascade is initiated with the binding of the BMP ligand to BMPRII. BMPRII recruits and phosphorylates the GS box (Gly-Ser box) of BMPRI, activating BMPRI (KirkerHead. 2000). Activated BMPRI then interacts with intracellular mediators of the Mothers against decapentaplegic homologs (SMAD) family. BMPRI phosphorylates a receptor-regulated SMAD or R-SMAD (i.e. SMAD1, SMAD5 or SMAD 8). The BMP-SMAD complex is released from the receptor heterodimer and interacts with common-partner SMAD or co-SMAD4, in the cell cytoplasm. The heteromeric SMAD complex then translocates to the nucleus, interacting with DNA-binding cofactors to modulate BMP-related gene expression (Fig. 4) (Rosen. 2006). Once BMP-related gene expression is initiated, the R-SMAD becomes proteolytically degraded with the involvement of factors such as Smad ubiquitin regulatory factors (SMURFs) (Miyazono et al., 2000; Kavsak et al., 2000). Aside from the SMAD signaling pathway, BMPs can also activate intracellular substrates of the Mitogen-activated protein kinase (MAPK) family and other downstream pathways (Wan et al., 2005).

\subsection{3-Downstream Pathways: ERK-MAPK Pathway}

Many ERK-MAPK members are involved in the crosstalk with BMP signaling pathway members; they can phosphorylate different SMADs and participate in the regulation of BMP activity on an intracellular level. The ERK- 
MAPK pathway is initially activated by the binding of ligands, such as Epidermal growth factor (EGF) or Hepatocyte growth factor (HGF), with tyrosine kinase receptors (von Bubnoff et al., 2001). The activated ERK kinase then phosphorylates serine residues of the conserved PXSP motifs that are present in the linker region of SMAD1, SMAD2 and SMAD 3. Furthermore, the activated ERK kinase can also phosphorylate other regions of SMAD members, such as the MH1 domain of SMAD2. However, the exact mechanism of ERK-MAPK signaling still remains poorly understood (Derynck et al., 2003). 


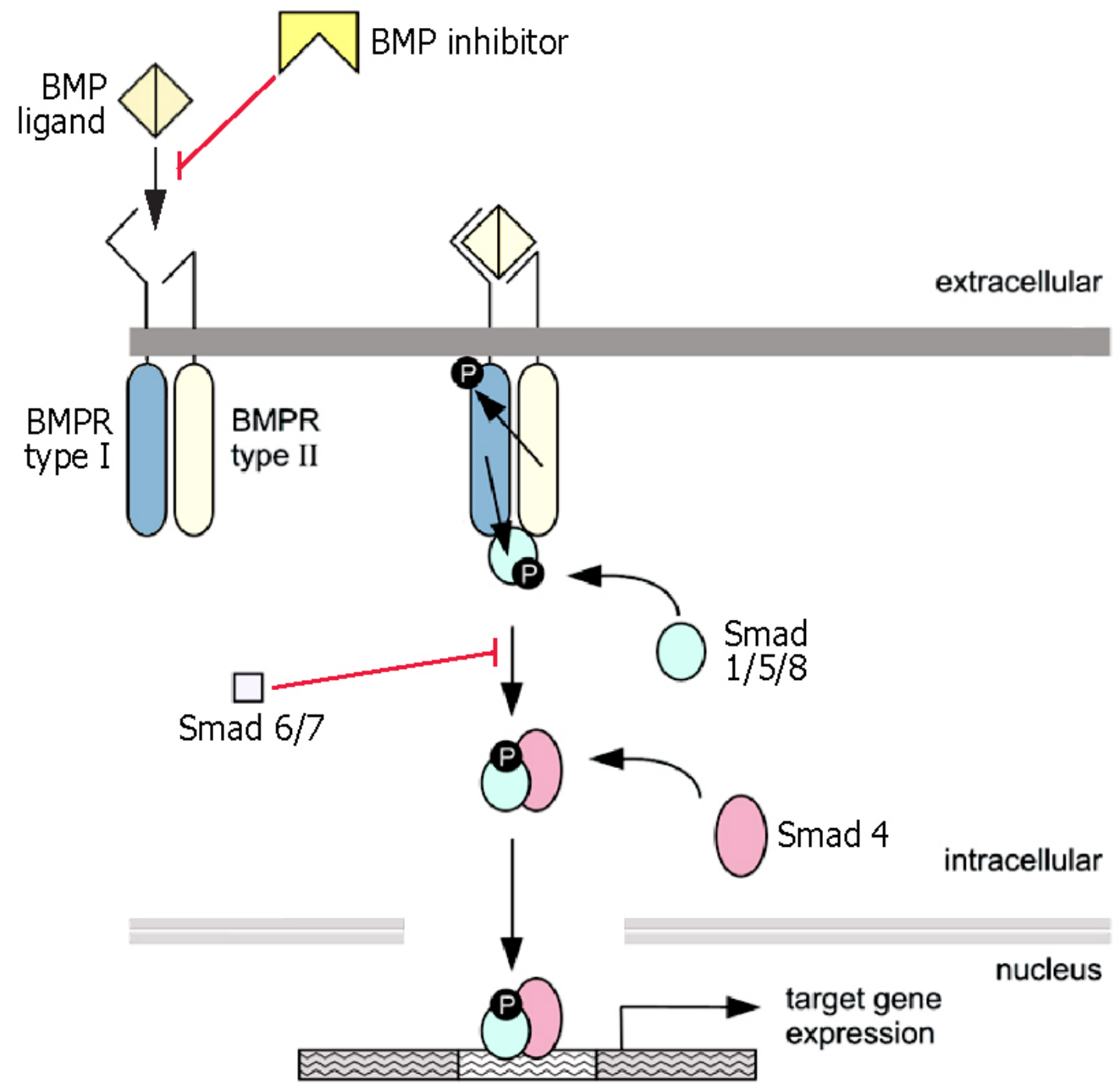

Figure 4 BMP Signaling Pathway

The BMP signaling pathway is initated with the interaction of a BMP ligand and two bone morphogenetic protein receptors (BMPR Type I \& BMPR Type II) that are serine/threonine kinase receptors. Once, a BMP ligand binds to BMPRII, BMPRIl recruits and transphosphorylates BMPRI. Phosphorylated BMPRI interacts with intracellular substrates from the Mothers against Decapentaplegic Homologs (Smad) family. Activated BMPRI then phosphorylates receptor-regulated Smad 1, 5 or 8 . The phosphorylated Smad 1, 5 or 8 then interacts with common-partner Smad 4 and this heteromeric complex translocates to the nucleus to regulate BMP-related gene expression. BMP activity can also be inhibited by extracellular antagonists (Noggin, Chordin, Follistatin, Gremlin \& Sclerostin) or intracellular antagonists (Smad 6 or 7 ). (Figure adapted from Balesman et al., 2002) 


\subsection{4-BMP Antagonists}

BMP activity is highly regulated by antagonists to ensure proper bone development. There are three groups of extracellular BMP antagonists:1- proregions, 2- ligand antagonists and 3-receptor antagonists. Pro-regions interact with the mature peptide (Rosen. 2006). However, studies with BMP2 and BMP9 have shown that Pro-regions are inefficient inhibitors of osteogenesis as this group of antagonists can easily get degraded via proteolytic cleavage (Bogdanovitch et al., 2005; Brown et al., 2005; Hillger et al., 2005). The second group of BMP inhibitors include ligand antagonists such as Noggin, Chordin, Follistatin, Gremlin and Sclerostin that bind to the BMP ligand, preventing the initiation of the BMP signaling cascade. Receptor antagonists like BMP3 and Inhibin, bind the BMP receptor to prevent BMP ligand-receptor interaction. The ligand and receptor antagonists prevent the osteogenic-related functions of BMP. In addition, inhibitory SMADs (SMAD6 \& SMAD7) are BMP antagonists that interfere with BMP activity on an intracellular level (Rosen. 2006).

\subsection{5-Functions of BMPs}

Aside from ectopic bone formation, BMPs possess many other roles in the body: such as their involvement in the development of the musculoskeletal system, the nervous system and the organogenesis of tooth buds, eyes, lungs, kidneys, the prostate and gonads (Kirker-Head. 2000). In addition, BMPs are also involved in skeletal patterning during embryogenesis. Other skeletal functions of BMPs include the induction of mesenchymal cell differentiation towards the chondroblast and osteoblast lineage, involvement in various stages of 
endochondral ossification, inhibition of bone marrow stromal cell differentiation into adipocytes and their involvement in the expression of extracellular matrix proteins (Rosen et al., 1996).

\subsection{6-Effects of BMP Administration during DO}

Numerous studies have shown that recombinant forms of BMP2 and BMP7 have successfully increased the rate of bone formation in different animal models of DO. Yonezawa and colleagues monitored the effects of administering recombinant human BMP2 (rhBMP2) mixed with a collagen gel to a rabbit model of mandibular DO and noticed that the rhBMP2-treated rabbits contained advanced bone formation compared to the non-injected controls (Yonezawa et al., 2006). In another study, a single dose of rhBMP7 injected into a rat tibial model of DO dramatically enhanced bone formation in the distracted zone (Mizumoto et al., 2003). Thus, BMP2 and BMP7 are excellent candidates for the acceleration of the consolidation period of DO.

Li and al. studied the effects of rhBMP2 administration in a rabbit model of DO. Distraction osteogenesis was performed on the tibia of rabbits. Postosteotomy, the operated rabbits were left to rest for a 7 day latency period and distracted for 10 days using a distraction rate of $2.0 \mathrm{~mm} /$ day. A fast distraction rate was used on the rabbits to develop a poor bone healing model. Recombinant human BMP2 was delivered to the rabbits using two methods: 1-delivery of rhBMP2 (dissolved in a buffer) using an absorbable collagen sponge that was implanted into the lengthened zone at the end of distraction $(5 \mathrm{ul}$ of $1.5 \mathrm{mg} / \mathrm{ml}$ 
solution of rhBMP2) and 2-percutanous injection of rhBMP2 dissolved in a buffer $(0.1 \mathrm{ml}$ of $75 \mathrm{ug}$ of rhBMP2). Controls underwent distraction using the same conditions as the experimental group and were implanted with a buffer-soaked collagen sponge or injected with the buffer solution alone. Radiological images showed that both methods of rhBMP2 delivery enhanced bone formation within the distracted gap. At 5 and 14 days post-rhBMP2 treatment, the bone mineral content of the distracted bone was significantly higher in the rhBMP2-treated rabbits than the controls. Furthermore, at 14 days post-treatment rhBMP2injected rabbits contained an increase in the average bone volumetric density compared to the buffer-injected control group. By 28 days post-treatment, the rhBMP2-injected rabbits contained stronger bone regeneration than the rhBMP2implanted rabbits. Overall, the rhBMP2-injected rabbits exhibited better bone formation in the distracted zone than the rhBMP2-implanted group, demonstrating that rhBMP2 delivery during DO depends on numerous factors including the biodegradability, structural integrity $\&$ immunogenicity of the scaffold and the rate of rhBMP-2 release from the scaffold. The administration of rhBMP2 in a rabbit model of DO seemed to induce rapid osteoblast differentiation and recruit other cellular growth factors to the distracted site, enhancing bone formation and shortening the consolidation phase of DO (Li et al., 2002).

Hamdy and colleagues studied the effects of BMP7 administration on a rabbit model of DO. Previous studies conducted by Hamdy's group using this model showed that peak expression for BMP2, BMP4 and BMP7 occurred during the distraction period that gradually decreased by the consolidation phase. Based 
on these findings, they proposed that early consolidation would be the ideal time for BMP7 administration to obtain accelerated bone formation. Tibial lengthening was performed on white New Zealand rabbits (7 day latency period, 21 day distraction period using a distraction rate of $0.5 \mathrm{~mm}$ every 12 hours and 21 consolidation period). A single shot of BMP7 was injected in the distracted site during early consolidation using three different doses: $80 \mathrm{ug}, 800 \mathrm{ug}$ and $2000 \mathrm{ug}$. Two controls were used in this study: Group 1-control rabbits underwent distraction without BMP7 injection and Group-2-control rabbits were distracted and were only injected with acetate buffer. Biomechanical testing, histomorphometric and densitometric analysis showed that the highest dose of BMP7 induced a non-statistically significant increase in bone formation compared to the controls. However, such high doses of BMP would not be ideal for patient administration. Moreover, the timing of BMP administration during early consolidation was off and did not produce significant results. Further studies using immunohistochemistry showed that highest expression of the BMP7 receptors BMPR1a, BMPR1b \& BMPR2 peaked around early distraction and decreased by early consolidation. This discovery supported the fact that the timing of BMP7 administration was not favorable because there were not enough receptors available during early consolidation for receptor-ligand interaction necessary to stimulate bone formation within the distracted gap (Hamdy et al., 2003).

A follow-up to Hamdy's study was performed by Mandu-Hrit and colleagues analyzing the effects of BMP7 administration during early distraction 
in a rabbit model of DO. DO was performed on the rabbits using the same conditions as Hamdy's study, with the exception of the timing and dose of BMP7. Mandu-Hrit and colleagues injected 75 ug of BMP7 dissolved in acetate buffer into the distracted gap of rabbits 7 days post-distraction. Controls for this experiment underwent distraction but, were only injected with acetate buffer. Interestingly, radiological and densitometric results showed that the BMP7-treated rabbits had developed twice the amount of bone within the distracted gap compared to the controls, 3 weeks post-BMP7 treatment. The BMP7-treated rabbits also contained an increase in bone volume within the distracted gap from week 1 to week 3 post-treatment compared to the controls. In addition, immunohistochemical analysis showed an upregulation in BMP-related genes including BMP ligands, BMP receptors and other FGFs. Thus, the timing of BMP7 administration, early distraction, was optimal for accelerating the consolidation period of DO (Mandu-Hrit et al., 2006).

The application of exogenous BMP2 and BMP7 has shown to possess great osteogenic potential in pre-clinical and clinical studies of DO (Rengachary. 2002). However, one of the problems associated with the use of exogenous BMP is that large supraphysiological doses of BMPs have to be applied locally in order to obtain clinically significant results and such large doses may have unknown long term side effects (Haque et al., 2008). Therefore, a logical alternative to the application of exogenous BMPs during DO would be the manipulation of the endogenous BMP pathway. However, very little is known about the physiological role of endogenous BMPs during DO. Hence, the aim of this thesis is to 
investigate the role of BMP signaling during DO by using a heterozygous limbspecific BMP2 knockout mouse model of DO. 


\section{0-OBJECTIVE OF STUDY:}

In order to unequivocally demonstrate the role of BMP signaling during DO, we first monitored the expression of components of the pathway during DO in wild-type mice. Following these studies, we performed DO in mice with decreased BMP2 gene dosage (BMP2 ${ }^{f l /+ \text { cre }}$ mice; heterozygous for BMP2 in the developing limbs). Tibial samples were analyzed using $\mu \mathrm{CT}$, Faxitron x-ray, immunohistochemistry, histology, Real Time- quantitative PCR and biomechanical testing. 


\section{0-MATERIALS \& METHODS}

\section{1-Bmp2 breeding}

The conditional BMP2 knockout mice used in this study were provided by Dr. Vicki Rosen (Harvard School of Medicine, Boston, MA). The conditional BMP2 knockout mice were generated by intercrossing mice containing a floxxed Bmp2 allele with Prx1::cre transgenic mice. Upon breeding these mice, the cre recombinase enzyme recognized the loxP sites flanking exon 3 of Bmp2 and excised this portion of the gene out. The remaining ends of the cleaved DNA segment were ligated together forming one continuous strand (Zhang et al., 1996). Under the control of the Paired-related homeobox-1 (Prx1) enhancer, Bmp2 was inactivated in the conditional BMP2 knockout mice early during limb bud development (Tsuji et al., 2006).

\section{2-Genotyping of Mice}

\subsection{1-DNA Extraction from Mouse Tails}

Tail clips were collected from three-week old BMP2 knockout mice and added to eppendorf tubes containing $500 \mu \mathrm{l}$ of lysis buffer $(100 \mathrm{ml}$ Tris- $\mathrm{HCl} \mathrm{pH}$ 8.5, $5 \mathrm{mM}$ EDTA, $0.2 \% \mathrm{SDS}$ and $200 \mathrm{mM} \mathrm{NaCl})$. Proteinase $\mathrm{K}(10 \mathrm{mg} / \mathrm{ml})$ was added to the samples and mixed using a platform agitator overnight at $55^{\circ} \mathrm{C}$. The following day, samples were spun down at $12000 \mathrm{rpm}$ for 10 minutes. After centrifugation, the supernatant was collected in new eppendorf tubes. A volume of $500 \mu \mathrm{l}$ of isopropanol was added to the samples to precipitate the DNA. The samples were mixed by inversion and allowed to stand at room temperature for 10 minutes. The samples were centrifuged at $12000 \mathrm{rpm}$ for 5 minutes. The DNA 
pellets were washed with $500 \mu$ l of cold $70 \%$ ethanol and spun down at 12000 rpm for 5 minutes. After removal of ethanol, the samples were allowed to dry at room temperature for 30 minutes. The DNA pellets were resuspended in $200 \mu 1$ of tail TE (10 mM-HCl, $0.1 \mathrm{mM}$ EDTA, pH 7.5). The tail DNA was kept at $55^{\circ} \mathrm{C}$ for a few hours to help the DNA dissolve in solution and stored at room temperature for long-term storage.

\subsection{2-PCR Genotyping}

Limb-specific conditional BMP2 knockout mice were genotyped using bmp2 and cre primers. The bmp2 primers (AHP2-9:

5'GTGTGGTCCACCGCATCAC-3' and AHP2-35: 5'-

GGCAGACATTGTATCTCTAGG-3') yielded a 474 bp amplimer from the wildtype allele and a $545 \mathrm{bp}$ fragment from the floxed allele. The cre primers (Forward: 5'-GCCTGCATTACCGGTCGAATGCAACGA-3' and Reverse: 5'GTGGCAGATGGCGCGGCAACACCATT-3') yielded a 726 bp amplimer. The PCR reactions were carried out in thermowell tubes containing $2.5 \mu 1$ of 10x PCR Buffer- $\mathrm{MgCl}_{2}(200 \mathrm{mM}$ Tris- $\mathrm{HCl} \mathrm{pH} 8.4,500 \mathrm{mM} \mathrm{KCl}, 1.25 \mathrm{ml} \mathrm{MgCl}$ ), $2.5 \mu \mathrm{l}$ of $2 \mathrm{mM}$ dNTP, $2.5 \mu \mathrm{l}$ of each bmp2 or cre primer set, $0.75 \mu \mathrm{l}$ of $50 \mathrm{mM} \mathrm{MgCl}_{2}$, $0.25 \mu 1$ of $5 \mathrm{U} / \mu 1$ Taq DNA polymerase (Invitrogen, Carlsbad, CA) $13 \mu \mathrm{lof} \mathrm{dH}_{2} \mathrm{O}$ and $1 \mu \mathrm{l}$ of tail DNA. The PCR reactions were amplified using a GeneAMP PCR System 9700 thermal cycler (Applied Biosystems, Singapore). PCR conditions included heating for 5 minutes, 35 cycles of denaturation at $94^{\circ} \mathrm{C}$ for 30 seconds, annealing at $58^{\circ} \mathrm{C}$ for 30 seconds and extension at $72^{\circ} \mathrm{C}$ for 45 seconds, with 
further extension at $72^{\circ} \mathrm{C}$ for 7 minutes. The PCR products were separated via electrophoresis using a 1.3\% UltraPure Agarose (Invitrogen) gel.

\section{3-Operative Protocol}

The surgical procedure was approved by the McGill University Animal Care Committee. DO was performed on wild-type (BMP2 $\left.{ }^{f l /+}\right)$ and heterozygous (BMP2 $2^{f l /+c r e}$ ) conditional knockout mice that were 2-3 months of age, using a miniature Ilizarov fixator adapted from Jill Helms study (Tay et al., 1998). Mice were subcutaneously injected with $0.1 \mathrm{ml}$ of (1mg/kg-Sigma) of buprenorphine and then anesthetized with isoflurane using a Fortec pump (Cyprane Keighley, England) throughout surgery (approximately 45 minutes). After shaving the right leg, two $0.25 \mathrm{~mm}$ insect pins (Austerlitz, Marlborough, MA) were drilled $90^{\circ}$ apart into the proximal metaphysis of the right tibia. Both pins remained perpendicular to the tibia. The pins were secured into position using a ring and four hexagonal nuts. A second set of pins was drilled into the distal metaphysis of the right tibia approximately $12 \mathrm{~mm}$ away from the proximal set of pins. Three rods were inserted through the first ring of the mini-Ilizarov fixator (Paolo Alto, CA) and secured into position. A second ring was placed through the three rods and secured onto the distal set of pins using hexagonal nuts. Once the minifixator was installed into place, a small incision was made along the diaphysis of the right tibia using a no.11 surgical scalpel (Fisher Scientific, Osaka, Japan). A small hole was drilled into the middle of the diaphysis using an insect pin to weaken the bone and facilitate the osteotomy. Using the scalpel, the bone was cut along the hole to complete the osteotomy. The fractured ends of the bone were 
aligned and the incision was closed using coated vicryl sutures (J385H-Johnson \& Johnson, North Ryde, NSW). Animals were subcutaneously injected with $0.1 \mathrm{ml}$ of buprenorphine and checked regularly throughout a 5 day latency period for pain management before initiating distraction. Mice were distracted for 12 days using a distraction rate of $0.2 \mathrm{~mm}$ every 12 hours. The distraction rate was previously used by Jill Helm's group (Tay et al., 1998). The new distracted bone was allowed to consolidate for a period of 34 days. Mice were euthanized by using carbon dioxide or performing cervical dislocation under anesthesia. Distracted tibial samples were collected at various time points: 11 days (middistraction phase), 17 days (end of distraction phase), 34 days (mid-consolidation phase) and 51 days (end of consolidation phase) for further analysis.

\section{4-Micro-Computed Tomography ( $\mu \mathrm{CT})$ \& Faxitron X-ray}

In preparation for micro-computed tomography $(\mu \mathrm{CT})$ and Faxitron x-ray, distracted bones collected from wild-type and heterozygous mice ( $\mathrm{n}=6$ per time point) were suspended in 4\% paraformaldehyde (PFA) $4 \mathrm{~g}$ of paraformaldehyde in $100 \mathrm{ml} \mathrm{1x}$ PBS) overnight at $4^{\circ} \mathrm{C}$. Samples were washed in 1x PBS for 30 minutes and consecutively dehydrated in graded solutions of $50 \%$ and $70 \%$ ethanol twice for one hour intervals at room temperature. Samples stored in $70 \%$ ethanol were taken to the Centre of Bone and Periodontal Research of McGill University for analysis.

$\mu \mathrm{CT}$ analysis was completed using the SkyScan 1072 (Aartselaar, Belgium) that has a $20-100 \mathrm{KeV} / 0-250 \mathrm{~mA}$ sealed, air-cooled, microfocus X-ray 
source with a polychromatic beam. The SkyScan 1072 was also equipped with a detector that contained a 12-bit, cooled CCD camera (1024 by 1024 pixels) coupled by a fiber optics taper to the scintillator. The distracted tibiae were scanned at $45 \mathrm{KeV} / 222 \mu \mathrm{A}$ with $25 \mathrm{X}$ magnification $(11.25 \mu \mathrm{m}$ pixel size $)$. Image reconstruction was performed using NRecon (1.4.4, SkyScan). Static histomorphometry parameters such as, tissue volume $\left(\mathrm{mm}^{3}\right)$, bone volume $\left(\mathrm{mm}^{3}\right)$, bone volume/tissue volume (BV/TV \%), trebecular number $(1 / \mathrm{mm})$, trabecular separation $(\mathrm{mm})$ and trabecular thickness $(\mathrm{mm})$ were measured using the CT Analyser (1.8.0.2, SkyScan). Furthermore, the Faxitron MX-20 was used to produce radiographs of the distracted tibiae.

\section{5-Immunohistochemical Analysis}

\subsection{1-Paraffin Embedding}

Collected tibial samples from 34 days (mid-consolidation phase) and 51 days (end of consolidation phase) were suspended in $4 \%$ PFA overnight at $4^{\circ} \mathrm{C}$. The following day, samples were washed in 1x PBS for 30 minutes. Samples were then submerged in a solution of $0.85 \%$ saline $/ 30 \%$ ethanol for 15 minutes. The samples underwent a gradual dehydration process by immersing them in solutions of $50 \%, 70 \%, 90 \%$ and $100 \%$ ethanol for 15 minute each. The dehydrated tibial samples were resuspended in solutions of 1:1 ethanol:xylene (Fisher Scientific) and xylene for 15 minutes each. Moreover, the samples were washed three times with molten paraplast (Oxford Labware, St. Louis, MO) and then kept in paraplast overnight at $55^{\circ} \mathrm{C}$ under vacuum. The samples were positioned in molten paraplast-containing cassettes and left to solidify at $4^{\circ} \mathrm{C}$ for 
several hours. After paraffinization, the blocks were trimmed at $0.7 \mu \mathrm{m}$ and sectioned longitudinally at $0.5 \mu \mathrm{m}$ using a Lecia RM 2255 microtome (Leica Microsystems, Richmond Hill, ON). Sections were warmed in a $30^{\circ} \mathrm{C}$ water bath for 30 seconds and then placed on Superfrost Plus slides (Scientific Device Laboratory, Des Plaines, IL).

\subsection{2-Immunohistochemistry}

Distracted tibial samples ( $\mathrm{n}=3$ per time point) were deparaffinized and blocked with $10 \%$ hydrogen peroxide for 10 minutes to inhibit endogenous peroxidase activity. The sections were washed with distilled water and 1x PBS (phosphate buffered saline). Following the washings, the samples were incubated in phosphate-buffered saline containing 10\% normal goat serum (Vector Labs, Burlingame, CA) in a humidified chamber for 20 minutes to block nonspecific binding. Sections were rinsed with $1 \mathrm{x}$ PBS and blocked once more using the avidin-biotin blocking kit (Vector, SP-2001). For immunostaining, commercially available polyclonal goat antibodies were used to detect BMP2, BMP7, BMPR1a, BMPR1b, BMPR2, ACTR1, ACTR2b \& BMP3 (Santa Cruz Biotechnology, Santa Cruz- $1 / 100$ dilution in 1\% normal goat serum). Distracted tissue sections were probed with the polyclonal goat antibody overnight at $4{ }^{\circ} \mathrm{C}$ in a humidified chamber. For negative controls, the primary antibody was omitted. After washing the slides with 1x PBS, sections were incubated with a biotinylated goat antimouse secondary antibody (Santa Cruz Biotechnology-1/400 dilution in 1\% normal goat serum) for 30 minutes at room temperature in a humidified chamber. Sections were washed with 1x PBS and stained using the avidin-biotin complex 
method (ABC kit from Vector Labs) for 30 minutes, followed by 3,3'diaminobenzidine tetrachloride-peroxidase revelation. Finally, sections were counterstained with Weigert's iron hematoxylin (Fisher Scientific-1\% hematoxylin in $95 \%$ ethanol, $5.8 \mathrm{~g}$ chloral ferric powder in $500 \mathrm{ml}$ deionized water-1\% $\mathrm{HCl}$ ) and mounted with Permount.

\section{6-Histological Analysis}

\subsection{1-MMA Embedding}

Distracted tibial samples were collected at 17, 34 and 51 days post-surgery and suspended in $4 \%$ PFA overnight at $4{ }^{\circ} \mathrm{C}$. The next day, samples were washed in 1x PBS for 30 minutes. The samples were gradually dehydrated by submerging them twice in solutions of $50 \%, 70 \%, 90 \%$ and $100 \%$ ethanol for one hour intervals at room temperature. The dehydrated samples were consecutively suspended in xylene three times for 40 minute intervals. These samples were then treated with varying concentrations of Methyl Methacrylate ( $0 \%$ to $4.5 \% \mathrm{MMA})$. Following this step, the tibial samples were placed in new vials containing $4.5 \%$ MMA and left to harden for a week at room temperature. The solidified MMA blocks were trimmed at $0.7 \mu \mathrm{m}$ and sectioned longitudinally at $0.5 \mu \mathrm{m}$ using a Leica microtome (Leica Microsystems). The tibial sections were place in Silane Plus slides (Scientific Device Laboratory) and left to dry overnight at $55^{\circ} \mathrm{C}$. The next day, the slides were deplastified using four washes of Ethylene Glycol Monoethyl Acetate (EGMA) for 15 minutes at room temperature. Following the deplastification phase, the slides were dried overnight at room temperature, ready for staining. 


\subsection{2-Goldner Trichome Staining}

The MMA embedded tibial sections were consecutively hydrated in $70 \%$ and $40 \%$ ethanol for 5 minutes each and rinsed with deionized water. The hydrated slides were stained with Weigert's Iron Hemtoxylin (Fisher Scientific1\% Hematoxylin in 95\% ethanol, $5.8 \mathrm{~g}$ Chloral-Ferric powder in $500 \mathrm{ml}$ deionized water-1\% $\mathrm{HCl}$ ) for 25 minutes and quickly rinsed with deionized water throughout 10 minutes. Following the washes, the sections were stained with Fushin-Ponceau (Fisher Scientific- 0.167 g Fushin acid, 0.667 g Ponceau in 500 $\mathrm{ml}$ deionized water) for 30 minutes, Orange $\mathrm{G}$ (Fisher Scientific- $10 \mathrm{~g}$ Orange $\mathrm{G}$ in $500 \mathrm{ml}$ deionized water) for 8 minutes and Light Green (Fisher Scientific- $1.5 \mathrm{~g}$ Light Green in $500 \mathrm{ml}$ deionized water) for 30 minutes. The slides were rinsed with $1 \%$ acetic acid in between stainings. After the last acetic acid wash, the slides were consecutively washed in 1:2 deionized water:tertiary butanol (20 seconds), butanol (twice for 20 seconds each), 1:2 butanol:xylene (15 seconds) and xylene $(15,10 \& 5$ seconds). Stained slides were mounted using Microkitt (Fisher Scientific) and allowed to dry overnight at room temperature. Pictures of the distracted zones were taken under $25 \mathrm{x}, 40 \mathrm{x}$ and 100x magnification using a Leica microscope (Leica Microsystems) attached to a Q-Imaging camera (Olympus DP70, Japan).

\section{7-Real Time PCR Analysis}

\subsection{1-RNA Extraction}

Distracted \& undistracted tibial samples were snap-frozen with liquid nitrogen and crushed using a mortar and pestle under an RNAse-free 
environment. All tools used for RNA extraction were sprayed with RNAse Zap (Ambion). The crushed tissue was suspended in $2 \mathrm{ml}$ of Trizol (Invitrogen) and further homogenized using a Polytron PT-MR 3000 (Kinematica) for 20 seconds at $20000 \mathrm{rpm}$. After a period of 5 minute incubation on ice at room temperature, $400 \mu 1$ of chloroform was added to the homogenized mixture and shaken vigorously by hand for 15 seconds. Following a 3 minute incubation period, samples were centrifuged at $12000 \mathrm{xg}$ for 15 minutes at $4^{\circ} \mathrm{C}$. The RNAcontaining aqueous phase was carefully collected into a new $2 \mathrm{ml}$ eppendorf tube. A total of $1 \mathrm{ml}$ of isopropyl alcohol was added to each sample for RNA precipitation. After a 10 minute incubation period at room temperature, the RNA samples were centrifuged at $12000 \mathrm{x}$ for 10 minutes at $4{ }^{\circ} \mathrm{C}$. The resulting RNA pellet from each sample was washed with $2 \mathrm{ml}$ of cold $75 \%$ ethanol in DEPC water by gently vortexing for a few seconds. Samples were centrifuged at $7500 \mathrm{x}$ $\mathrm{g}$ for 5 minutes at $4^{\circ} \mathrm{C}$ and vacuum-dried for 4 minutes. Dried RNA samples were resuspended in $25 \mu 1$ of RNAse-free water (Ambion). Samples were kept at $80^{\circ} \mathrm{C}$ for long-term storage. The concentration and purity of each RNA sample was measured using a ND-1000 Spectrophotometer (NanoDrop Technologies, Inc., Wilmington, DE) This RNA extraction method was provided by Invitrogen, Carsbad.

\subsection{2-Reverse Transcription}

RNA was extracted from distracted tibial samples from wild-type and of $11,17,34 \& 51$ days post-surgery ( $\mathrm{n}=3$ per time-point) and undistracted tibia of 1-week old wild-type BMP2 ${ }^{f /+}$ mice, heterozygous BMP2 ${ }^{f /+c r e}$ mice and 
homozygous BMP2 ${ }^{\text {flfl cre }}$ mice ( $\mathrm{n}=3$ per genotype). RNA samples were reverse transcribed using a high-capacity cDNA reverse transcription kit (Applied Biosystems, Foster City, CA). A total of $10 \mu \mathrm{l}$ of master mix (10x Reverse Transcription buffer, 10x Random Primer mix, 25x dNTP mix (100 mM), $50 \mathrm{U} / \mu 1$ MultiScribe Reverse Transcriptase) was loaded onto the wells of a 96-well optical plate. An equal volume of sample RNA was mixed into the wells. The plate was then loaded into the GeneAmp PCR System 9700 thermal cycler (Applied Systems) for reverse transcription.

\subsection{3-Real Time Quantitative PCR (RT-qPCR)}

Expression patterns of BMP and osteogenic markers in the distracted callus were quantified over different time points using RT-qPCR. Reverse transcribed mRNA collected from distracted \& undistracted samples were loaded into a 96-well plate and mixed with Universal Master Mix (Applied Biosystems), a specific TaqMan probe and RNAse free water. The 96-well plate was placed into a 7500 Real Time PCR system (Applied Biosystems) for RT-qPCR analysis. The markers measured included Bone morphogenetic proteins (BMP2, BMP3, BMP4, BMP6 \& BMP7), BMP receptors (BMPR1A, BMPR1B \& BMPR2), BMP antagonist (Gremlin \& Chordin) and Mothers against decapentaplegic drosophila homolog (SMAD1, SMAD2, SMAD3, SMAD4, SMAD5, SMAD6, SMAD7 \& SMAD9). Osteogenic markers included Collagen type I (Col1a1), Sex determining region Y-box 9 (Sox9), Runt-related transcription factor 2 (Runx2), Osterix (OSX), Osteocalcin (OCN) and Activating transcription factor-4 (ATF-4). GAPDH was used as an endogenous control to normalize all samples used in the 
RT-qPCR reaction. Relative quantification of the target $\mathrm{cDNA}$ was performed using Applied Biosystems' comparative $C_{t}$ method (ABI Prism 7700 Sequence Detection System User Bulletin \#2, 2001).

\section{8-Biomechanical Testing}

Distracted tibia from wild-type and heterozygous mice were collected at 51 days post-surgery, end of consolidation phase $(n=3)$. These lengthened tibias were wrapped in gauze and stored in $1 \mathrm{x}$ PBS at $4{ }^{\circ} \mathrm{C}$ until further analysis.

Samples underwent biomechanical testing using the three-point bending test at the Centre for Bone and Periodontal Research of McGill University. The three-point

bending test was conducted using the Mach- $1^{\mathrm{TM}}$ Micromechanical Systems device (Bio Syntech Canada, Inc., Laval, QC). The distracted bone was placed on its posterior surface, resting on two supports of the bending apparatus that lie $7.0 \mathrm{~mm}$ apart. A bending load was applied downwards on the mid-shaft of the lengthened tibia at a rate $50 \mu \mathrm{m} / \mathrm{s}$, until failure. These results were analyzed using the Mach$1{ }^{\mathrm{TM}}$ Motion \& Analysis software (Version 3.0.2, Bio Syntech Canada). A loaddisplacement curve was generated using this software to measure biomechanical parameters including stiffness $(\mathrm{N} / \mathrm{mm})$, ultimate force $(\mathrm{N})$, ultimate displacement (um) and work to ultimate failure $\left(\mathrm{N}^{*} \mathrm{~mm}\right)$.

\section{9-Western Blot Analysis}

\subsection{1-Protein Extraction from Bone Tissue}

The distracted tibial samples were collected from the five time intervals: 5 days (end of latency phase), 11 days (mid-distraction phase), 17 days (end of 
distraction phase), 34 days (mid-consolidation phase) and 51 days (end of consolidation phase). Samples were snap-frozen using liquid nitrogen. These samples were crushed using a mortar and pestle and suspended in $600 \mu \mathrm{l}$ of lysis buffer solution (20 mM Tris- $\mathrm{HCl} \mathrm{pH} \mathrm{7.4,} 150 \mathrm{mM} \mathrm{NaCl}$, Triton X-100 0.8\%, $1 \mathrm{mM}$ EDTA and distilled water). In addition, $1 \mu \mathrm{l}$ of protease inhibitor cocktail (1 mM PMSF, $0.15 \mathrm{U} / \mathrm{ml}$ Apoprotin, $10 \mu \mathrm{g} / \mathrm{ml}$ Leupeptin and $1 \mathrm{mM} \mathrm{NaVO}_{3}$ ) was added to each sample. Tissue samples were homogenized using a Polytron PTMR 3000 (Kinematica AG, Littau, Switzerland) at maximum level (20 $000 \mathrm{rpm})$ for 20 seconds and then placed on rotating nutator overnight at $4^{\circ} \mathrm{C}$. The next day, samples were centrifuged for 10 minutes at $500 \mathrm{x}$ g at $4^{\circ} \mathrm{C}$. After centrifugation, the supernatant from each sample was collected in eppendorf tubes. The pellet was resuspended in $600 \mu 1$ of lysis buffer and re-homogenized for 20 seconds at $20000 \mathrm{rpm}$ using the Polytron. The tissue samples were then centrifuged for 15 minutes at $500 \mathrm{xg}$ at $4^{\circ} \mathrm{C}$. Following centrifugation, the supernatant was pooled with the previously collected protein extract. The pooled extracts were spun down at $5000 \mathrm{rpm}$ for 10 minutes at $4^{\circ} \mathrm{C}$ in a microcentrifuge to remove any remaining bone tissue. The supernatant of each sample was collected in new eppendorf tubes. Protein precipitation was initiated by adding $300 \mu 1$ of Trichloroacetic acid (TCA) to each sample. The solutions were mixed 1-2 times by inverting the eppendorf tubes by hand and incubated on ice for 10 minutes at $4^{\circ} \mathrm{C}$. Following incubation on ice, the samples were spun down in a microcentrifuge for 5 minutes at $14000 \mathrm{rpm}$. The supernatant of each sample was removed using vacuum suction leaving a white protein film along the sides of each eppendorf tube. The precipitated protein samples were washed twice with 
$200 \mu 1$ cold acetone. Subsequently, the protein pellets were dried in a $95^{\circ} \mathrm{C}$ heat block for a period of 1 to 3 minutes. Dried protein pellets were resuspended in $1 \mathrm{x}$ Laemli buffer without DTT and kept at $-20^{\circ} \mathrm{C}$ for long-term storage.

\subsection{2-Western Blot}

Protein collected from distracted tibial samples were separated using gel electrophoresis on a $10 \%$ polyacrylamide gel. The separated proteins were transferred onto nitrocellulose membranes and blocked in $5 \%$ Bovine Serum Albumin (BSA)-0.1\% Tri-Phosphate Buffer Saline-Tween (TBS-T) for an hour. The membranes were probed with anti-phospo-Smad1 (Upstate, Lake Placid, NY1:100 dilution with $5 \%$ BSA-0.1\% TBS-T) for an hour at room temperature. Subsequently, the membranes were washed twice with $0.1 \%$ TBS-T and incubated with alkaline-phosphotase conjugated anti-rabbit $\operatorname{IgG}$ (1:5000 dilution in $1 \% \mathrm{BSA}-0.1 \% \mathrm{TBS}-\mathrm{T}$ ) for an hour at room temperature. Following incubation with the secondary antibody, the membranes were washed three times using $0.1 \%$ TBS-T and exposed to film. Following development, the membranes were stripped using stripping buffer (0.2 M Glycine, $\mathrm{pH} 2.5$ and $0.05 \%$ Tween 20 ) at $80^{\circ} \mathrm{C}$ for 20 minutes. The stripped membranes were briefly washed using $0.1 \%$ TBS-T and blocked with $5 \%$ BSA- $0.1 \%$ TBS-T for an hour. The membranes were re-probed with anti-Smad1 (Santa Cruz Biotechnology, Santa Cruz, CA-1:50 dilution in $5 \%$ BSA- $0.1 \%$ TBS-T) for 1 hour at room temperature. After two washes with $0.1 \%$ TBS-T, the membranes were probed with alkalinephosphotase conjugated anti-mouse IgG (1:5000 dilution in $1 \%$ BSA-0.1\% TBST) for an hour at room temperature. Following three washes with $0.1 \%$ TBS-T, 
the membranes were exposed to film. The membranes were subsequently stripped and re-probed five times with the following primary antibodies: rabbit anti-phospho-p44/42 MAPK (anti-phospho-ERK 1/2) (Cell Signaling Technology, Pickering, ON-1:400 dilution), rabbit anti- p44/42 MAPK(anti-ERK 1/2) (Cell Signaling Technology-1:200 dilution), mouse anti-GAPDH (Ambion, Austin, TX-5 ug/ml), rabbit anti-phospho-p38 MAPK (Cell Signaling Technology-1:500) and rabbit anti-p38 MAPK (Cell Signaling Technology-1:500) in $5 \%$ BSA-0.1\% TBS-T. Secondary antibodies were prepared to 1:5000 dilution in $1 \%$ BSA-0.1\% TBS-T.

\subsection{0-Statistical Analysis}

All data included in this thesis was graphed using GraphPad Prism version 5.0 software. Wild-type and mutant populations were compared using a one-way, non-parametric ANOVA test. A p-value $<0.05$ was considered to be statistically significant. 


\section{0-RESULTS}

\section{1- Surgical Success Rate of Conditional BMP2 Deficient Mice}

Distraction osteogenesis was performed on a total of 107 adult mice (57 wild-type BMP2 ${ }^{f l /+}$ mice and 50 heterozygous BMP2 ${ }^{f l /+c r e}$ mice). 40 of 57 $\mathrm{BMP} 2{ }^{f / /+}$ mice successfully survived DO, accounting for a $70 \%$ success rate post-surgery. The remaining $17 \mathrm{BMP} 2{ }^{f l /+}$ mice died during surgery due to surgical complications or died post-surgery due to inflammation or the development of a necrotic foot. Interestingly, the heterozygous mice had a higher success rate with DO post- surgery than the wild-type controls. 40 of 50 BMP2 $\mathrm{fl} / \mathrm{cre}$ mice survived DO, resulting in a $80 \%$ success rate post-surgery. The remaining $10 \mathrm{BMP} 2^{f l /+ \text { cre }}$ mice died due to surgical complications. Surgical complications included fracturing of the bone during pin insertion or osteotomy.

\section{2- Gene Dosage Study Results}

RT-qPCR analysis of BMP2 expression was performed on reverse transcribed mRNA collected from undistracted 1-week old wild-type BMP2 ${ }^{f l /+}$ mice, heterozygous BMP2 ${ }^{f l /+c r e}$ mice and homozygous BMP2 $2^{\text {flfl cre }}$ mice (Fig. 6). A decreasing trend in BMP2 expression was observed within all three genotypes of the conditional BMP2 knockout mice; as demonstrated by a statistically significant decrease in BMP2 expression between the BMP2 fl/fl cre and $\mathrm{BMP} 2^{f l /+}$ mice and between the BMP $2^{f l f l c r e}$ and BMP $2^{f l /+c r e}$ mice. These results showed a gene-dosage dependant reduction in BMP2 expression and confirmed the data of Tsuji and colleagues: RT-qPCR was used to monitor BMP2 mRNA expression at 3 and 10 days post-fracture in control, heterozygous and 
homozygous limb-specific BMP2 knockout mice. Fractures were induced in the femur of mice and secured with a pin for weight-bearing and movement. RTqPCR results from Tsuji’s study also showed gene-dosage effects of BMP2 expression: the control mice contained the highest levels of BMP2 expression at 3 and 10 days post-fracture, the heterozygous mice expressed intermediate levels of BMP2 during these two time points and lastly the homozygous mice expressed the lowest levels of BMP2 (Tsuji et al., 2006). 


\section{Endogenous BMP2 expression in limbs}

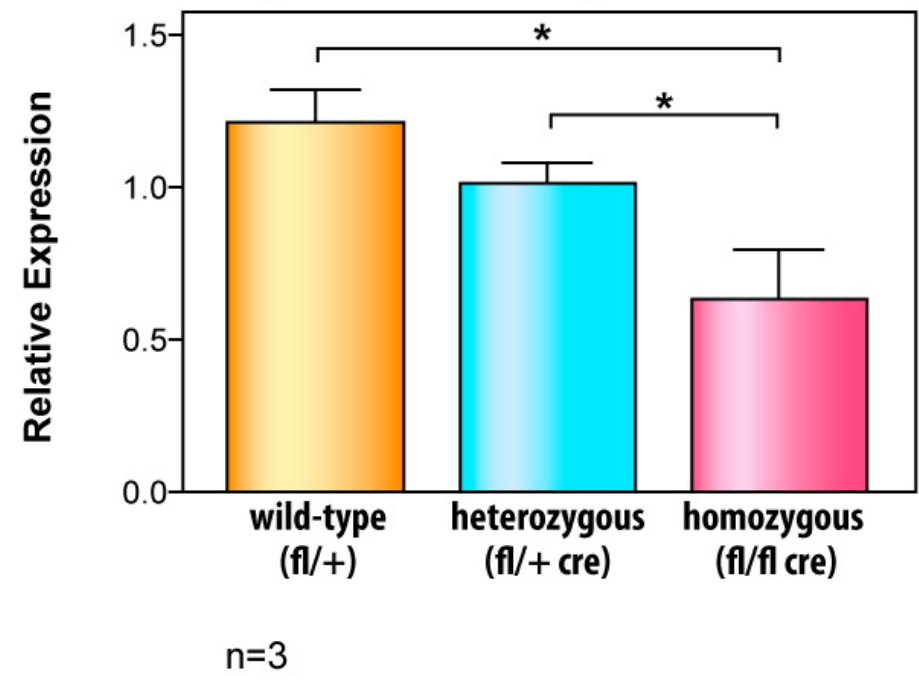

Figure 6 Undistracted BMP2 Deficient Mice Exhibit a BMP2 Gene Dosage Effect.

Reverse transcribed mRNA was collected from the limbs of undistracted one week old wild-type BMP2 $2^{\mathrm{fl} /+}$ mice, heterozygous $\mathrm{BMP} 2^{\mathrm{fl} /+}$ cre mice \& homozygous $\mathrm{BMP} 2^{\mathrm{f} / \mathrm{fl}}$ cre mice and analyzed using RT-qPCR. GAPDH was used as an endogenous control. A gene-dosage effect was observed in the BMP2 deficient mice: BMP2 inactivation corresponded to a statistically significant decrease in BMP2 levels in the heterozygous and homozygous mice, compared to the wild-type mice. No change in BMP2 levels was detected between the wild-type and heterozygous mice. ${ }^{*}, \mathrm{P}<0.05$. 


\section{3-Micro-Computed Tomography ( $\mu \mathrm{CT})$ \& Faxitron X-ray Results}

Distracted tibial samples were collected from wild-type BMP $2^{f l /+}$ mice and heterozygous BMP2 ${ }^{f l /+c r e}$ mice at $11,17,34 \& 51$ days and analyzed using $\mu \mathrm{CT}$ (Fig. 7A) and Faxitron x-ray (Fig. 7B). At $11 \& 17$ days (distraction phase), $\mu \mathrm{CT}$ analysis showed that there was no bone formation observed in the distracted gap of the wild-type BMP2 $2^{f l /+}$ and heterozygous BMP2 ${ }^{f l /+c r e}$ mice samples. By 34 days (mid-consolidation phase), callus formation was initiated in the distracted zone of the BMP $2^{f l /+}$ mice, and the two fractured bones were partially consolidated. During the mid-consolidation phase, the BMP $2^{f l+c r e}$ mice contained very little bone formation, and the bones remained relatively unconsolidated. By 51 days (end of consolidation phase), the two fractured ends in the BMP2 ${ }^{f l /+}$ mice were fully consolidated. Contrarily, during late consolidation, the BMP $2^{f l /+c r e}$ mice contained a partially consolidated distracted gap.

Static histomorphometry parameters were also measured by $\mu \mathrm{CT}$ analysis (Table 1). No significant difference was observed in BV/TV, trabecular number, trabecular separation and trabecular thickness, between the wild-type and heterozygous mice at 11,17 and 34 days post-surgery. However towards the end of consolidation, poor bone healing was observed in the BMP2 ${ }^{f l / c r e}$ mice as supported by a statistical significant increase in trebecular separation (Fig. 8A) and decrease in trebecular number (Fig. 8B). In addition, an increase in BV/TV was seen in the control BMP2 ${ }^{f l /+}$ mice compared to the heterozygous BMP2 $2^{f l /+}$ cre 
mice. No significant change was detected in trabecular thickness between the wild-type and heterozygous mice at 51 days.

Faxitron x-ray was used as a method to confirm the $\mu \mathrm{CT}$ results (Fig. 7B). The Faxitron x-ray images provided better resolution of the quality of bone development throughout the consolidation phase of DO. During the distraction phase, the X-ray images of the wild-type BMP $2^{f l /+}$ samples revealed a clear distracted gap in between two bony fragments. During consolidation, the distracted gap of the wild-type mice was gradually replaced with solid calcified tissue, fusing the two fractured ends of the bone together. In comparison, from the distraction phase to early consolidation, $\mathrm{x}$-ray images of the BMP $2^{f l /+c r e}$ showed that the heterozygous mice contained very little bone within the distracted zone. By late consolidation, the x-ray images of the heterozygotes showed that the osteotomy site had partially consolidated, indicative of impaired bone healing. 


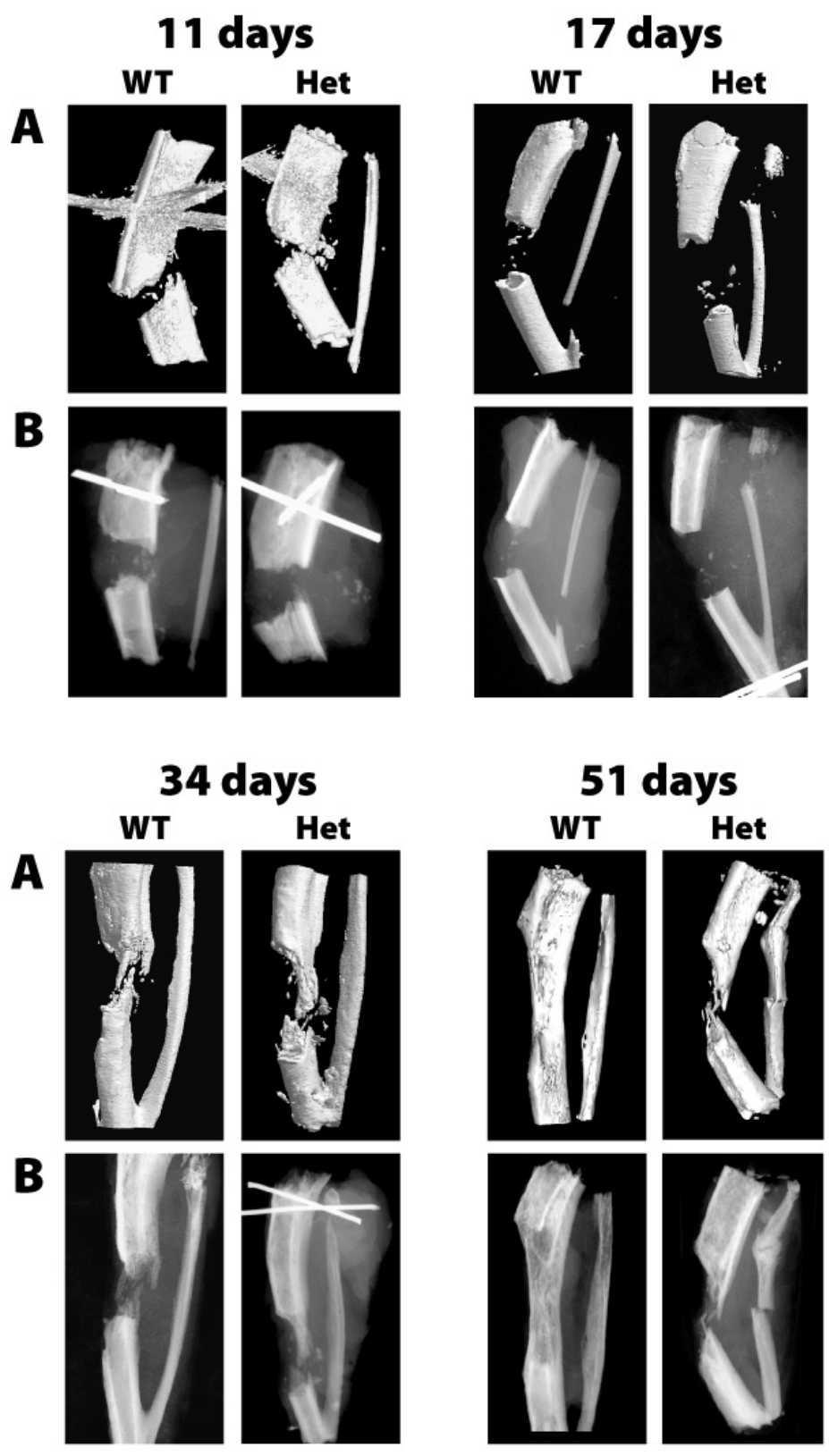

Figure 7 Poor Bone Formation Was Observed During DO in the Heterozygous BMP2 Deficient Mice.

Distracted tibial samples were collected at 11 days (mid-distraction phase), 17 days (end of distraction phase), 34 days (early consolidation phase) and 51 days (end of consolidation phase) post-surgery and analyzed using (A) $\mu \mathrm{CT}$ and (B) Faxitron x-ray. There was no significant difference in bone formation between the wild-type BMP2 $2^{\mathrm{f} /+}$ mice and heterozygous $\mathrm{BMP2}{ }^{\mathrm{fl} /+}$ cre mice at 11 \& 17 days postosteotomy. At 34 days, the wild-type and heterozygous mice demonstrated partial consolidation. However, at 51 days, the heterozygous mice showed a delay in consolidation with partial fusion of bony fragments compared to the wild-type samples that were fully consolidated. 
Table 1: $\mu$ CT Analysis of Wild-Type \& Heterozygous BMP2 Deficient Mice.

\begin{tabular}{|c|c|c|c|c|c|c|c|c|}
\hline & \multicolumn{2}{|c|}{11 days } & \multicolumn{2}{|c|}{17 days } & \multicolumn{2}{|c|}{34 days } & \multicolumn{2}{|c|}{51 days } \\
\hline & WT & Het & WT & Het & WT & Het & WT & Het \\
\hline Tissue Volume-TV (mm^3) & 9.371085 & 7.797865 & 24.35504 & 19.98558 & 10.06985 & 14.74117 & 25.23202 & 19.45774 \\
\hline Bone Volume-BV (mm $\left.{ }^{\wedge} 3\right)$ & 0.160123 & 0.11889 & 0.486595 & 0.447992 & 0.456673 & 0.936365 & 3.015048 & 2.27589 \\
\hline BV/TV (\%) & 2.54188 & 2.6729 & 1.58292 & 1.685033 & 4.527028 & 6.674693 & 12.08007 & 8.066395 \\
\hline Trabecular Thickness (mm) & 0.105992 & 0.099138 & 0.12197 & 0.131212 & 0.141132 & 0.169688 & 0.174585 & 0.224465 \\
\hline Trabecular Number (1/mm) & 0.23387 & 0.253553 & 0.116877 & 0.13147 & 0.303213 & 0.366708 & 0.647168 & 0.34042 \\
\hline Trabecular Separation (mm) & 0.742892 & 0.699758 & 1.687852 & 1.745193 & 1.336975 & 1.623127 & 0.720015 & 0.996188 \\
\hline
\end{tabular}

$\mu C T$ analysis of static histomorphometric parameters was performed on distracted tibial samples from four time points: 11 days (mid-distraction phase), 17 days (end of distraction phase), 34 days (midconsolidation phase) \&51 days (end of consolidation phase). 
A

Trabecular Separation

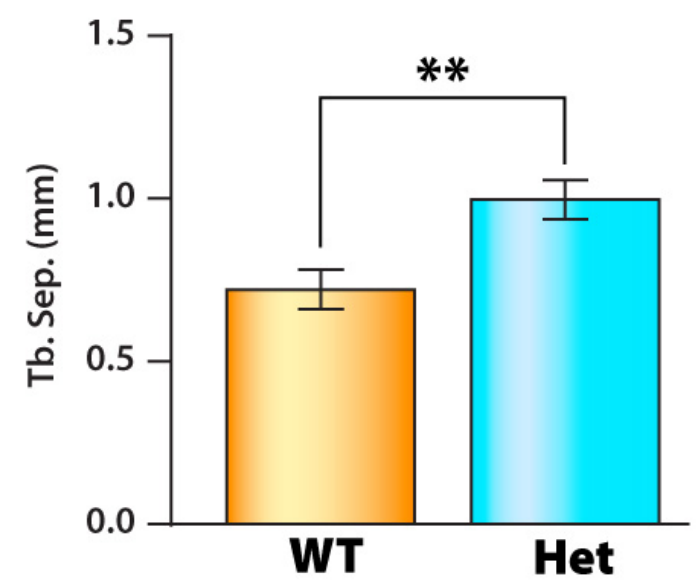

B
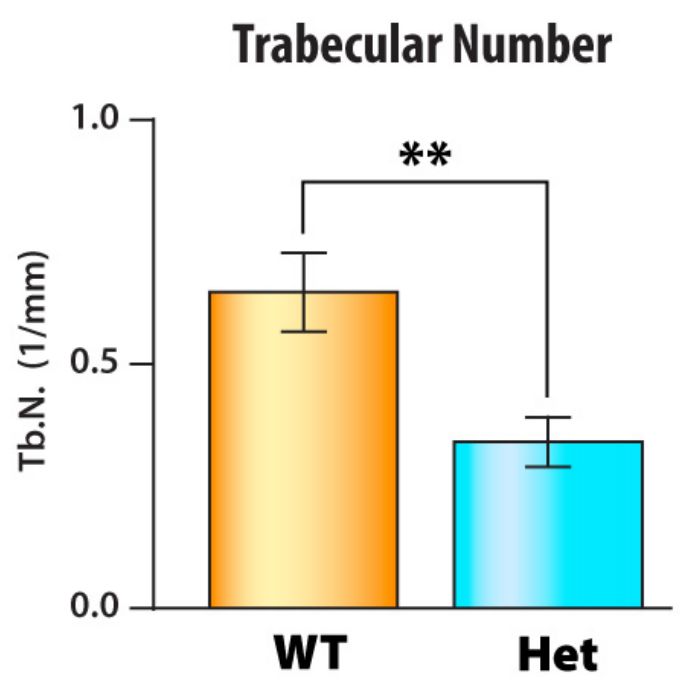

Figure 8 Static Histomorphometric Parameters Revealed Heterozygous BMP2 Deficient Mice Had Poor Bone Healing Patterns During the End of Consolidation. Distracted samples collected at 51 days post-surgery revealed a statistically significant increase in trabecular separation and decrease in trabecular number, indicating poor bone formation in the heterozygous mice during the end of consolidation phase of $\mathrm{DO}$. **, $\mathrm{P}<0.01$. 


\section{4-Immunohistochemistry Results}

Sections of distracted tibial samples collected at 34 and 51 days postsurgery of wild-type and heterozygous mice were analyzed using immunohistochemistry (Table 2). The tissue distribution of BMP2 (Fig. 9), BMP3, BMP7, BMPR1a, BMPR1b, BMPR2, ACTR1 \& ACTR2b expression was studied in the distracted region. Most of the positively stained cells were chondrocytes localized in the distracted region. A semi-quantitative method was used to further examine the immunohistochemical results. This technique involved grading gene expression based on the amount of cells that stained positively for a selected gene. The grading scheme included: + represented $>$ $25 \%$ of the cells stained positively for the gene of interest, ++ symbolized 25 to $50 \%$ of cells stained positive, +++ signified 25 to $75 \%$ of cells stained positive, ++++ represented more than $75 \%$ of cells stained positive, lastly - denoted no significant staining was present of the selected gene in the cell line (Haque et al. 2006). At 34 days (mid-consolidation phase), the heterozygous mice exhibited a reduction in BMP2, BMP7, BMPR1a, ACTR1, ACTR2b expression. Increased BMPR1b expression was detected in the heterozygotes during early consolidation. There was no difference observed in BMP3 and BMPR2 levels between control $\mathrm{BMP} 2^{f l /+}$ mice and heterozygous BMP $2^{f l /+c r e}$ mice at 34 days post-surgery. At 51 days (end of consolidation phase), the BMP2 ${ }^{f l /+ \text { cre }}$ mice contained an increase in BMP7, BMPR1b and ACTR2 expression and a reduction in BMP2 expression. No changes in BMP3, BMPR2 and ACTR1 expression levels were noted during late consolidation. The decrease in BMP2 protein expression during the 
consolidation phase further confirmed the gene-dosage effect present in the conditional BMP2 deficient mice 
Table 2: Immunolocalization of BMP Factors in Chondrocytes Present in the Distracted Zone of Wild-Type and Heterozygous BMP2 Deficient Mice.

\begin{tabular}{|r|c|c|c|c|}
\cline { 2 - 5 } \multicolumn{1}{c|}{} & \multicolumn{4}{c|}{ Consolidation } \\
\cline { 2 - 5 } & \multicolumn{2}{c|}{34 days } & \multicolumn{2}{c|}{51 days } \\
\hline Gene & WT & Het & WT & Het \\
\hline BMP Ligands & & & & \\
BMP2 & ++ & + & ++ & + \\
BMP7 & ++ & + & + & ++ \\
\hline BMP Receptors & & & & \\
BMPR1a & ++ & + & - & + \\
BMPR1b & ++ & ++++ & + & ++ \\
BMPR2 & +++ & +++ & + & + \\
ActR1 & ++++ & + & ++ & ++ \\
ActR2b & +++ & ++ & + & ++ \\
\hline BMP3 & + & + & + & + \\
\hline BMP Antagonist & & & & \\
\hline
\end{tabular}

Staining of chondrocytes in distracted zone, -: no positive staining, + : less than $1 / 4$ of cells stained positive, $++: 1 / 4$ to $1 / 2$ of cells stained positive, $+++: 1 / 2$ to $3 / 4$ of cells stained positive, and ++++ : more than $3 / 4$ of cells stained positive.

Distracted tibial samples were collected at 34 days (mid-consolidation phase) \& 51 days (end of consolidation phase) and analyzed using immunohistochemistry. Chondrocyte staining of different BMP pathway members was graded using a semi-quantitative method listed below table 2. At 34 days, BMP2, BMP7, BMPR1 a, ActR1 \&ActR2b expression was decreased in the heterozygous samples (with the exception of BMPR 1b expression that was increased). No changes were observed in BMPR2 \& BMP3 expression during early consolidation. At 51 days, heterozygotes contained an increase in BMP7, BMPR1b \& ActR2b expression and a reduction in BMP2 expression. No changes were observed in ActR1 \& BMP3 levels between the heterozygous mice \& wild-type controls. 


\section{BMP2 Expression}

34 days
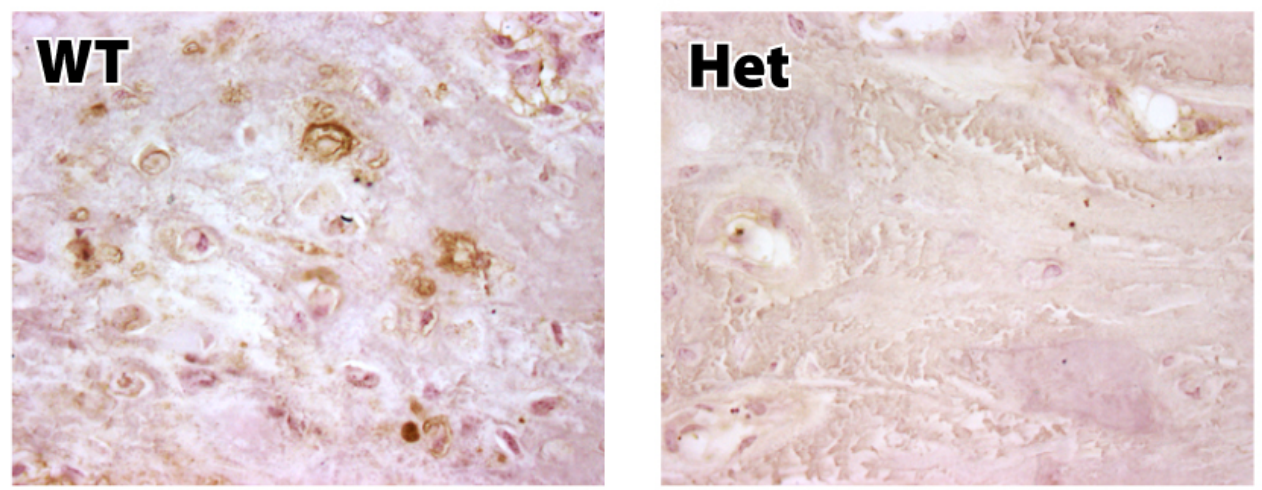

51 days
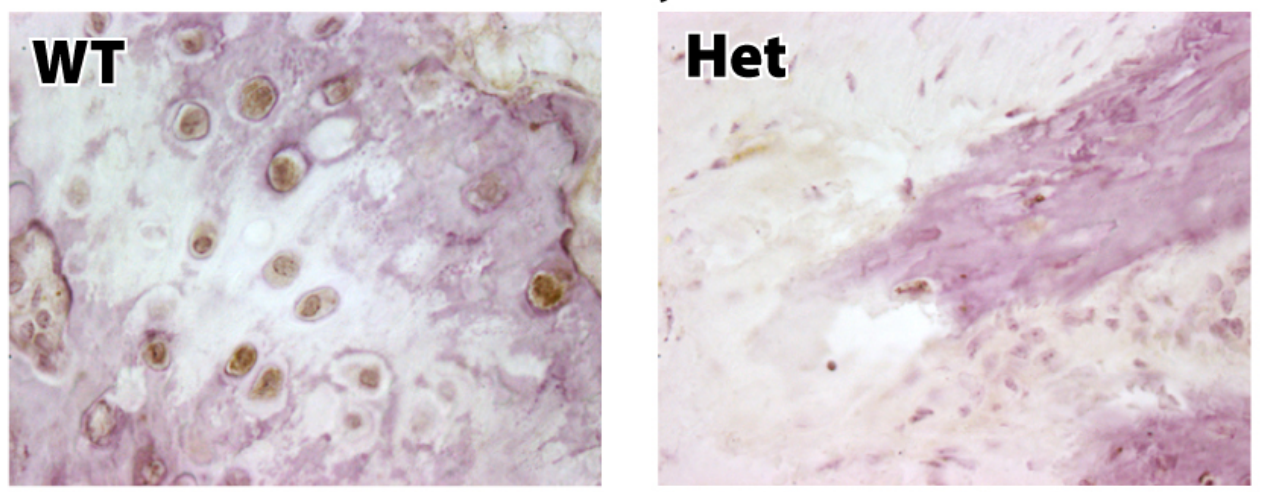

Figure 9 Immunohistochemical Images of BMP2 Expression in Heterozygous BMP2 Deficient Mice.

Immunohistochemical images of $34 \& 51$ days of heterozygous and wild-type distracted samples were taken at $40 \mathrm{x}$ magnification. These images support the finding that the $\mathrm{BMP} 2 \mathrm{fl} /+\mathrm{cre}$ mice contained a gene-dosage dependant reduction in BMP2 protein expression during the consolidation phase of DO. 


\section{5-Histological Results}

Half of the samples that were used for $\mu \mathrm{CT}$ and radiological analysis were later embedded in MMA for histological analysis. Distracted samples of control $\mathrm{BMP} 2{ }^{f l /+}$ mice and heterozygous BMP2 ${ }^{f l /+c r e}$ mice collected at $17,34 \& 51$ days post-osteotomy were sectioned and Goldner Trichome stained. Pictures were taken at the center of distracted zone at 25x and 100x magnification. Mineralized tissue stained green and non-mineralized tissue appeared red in the slides. At 17 days post-osteotomy (end of distraction phase) (Fig. 10), histological images revealed that bone formation was initiated at both fractured ends of the control sample, showing good bone healing patterns in the BMP2 ${ }^{f l /+}$ mice. At 17 days, no mineralized tissue was present in the callus of the heterozygotes. A closer magnification of the heterozygous distracted zone showed the presence of fibrous tissue in the callus, indicating that endochondral ossification may be the predominant method of bone development for the heterozygotes during the end of distraction. At 34 days (Fig. 11), early consolidation, the osteotomy site of the $\mathrm{BMP} 2^{f l /+}$ mice contained large areas of newly developed calcified tissue. A closer magnification of the control samples revealed that osteoblasts deposited osteoid (highlighted in purple in the stained sections) within areas of the new developing bone. At 34 days, the callus of BMP2 ${ }^{f l /+ \text { cre }}$ samples contained very poor bone formation (stained light green), demonstrating very little mineralization had taken place within the distracted zone. At 51 days (Fig. 12), end of consolidation, the control histological images exhibited strong bone remodeling, and the callus was replaced with newly formed cortical and trebecular bone.

During late consolidation, the BMP $2^{f l /+c r e}$ samples contained less calcified tissue 
and lacked newly remodeled cortical and trebecular bone, demonstrating improper bone formation in the heterozygous mice. 

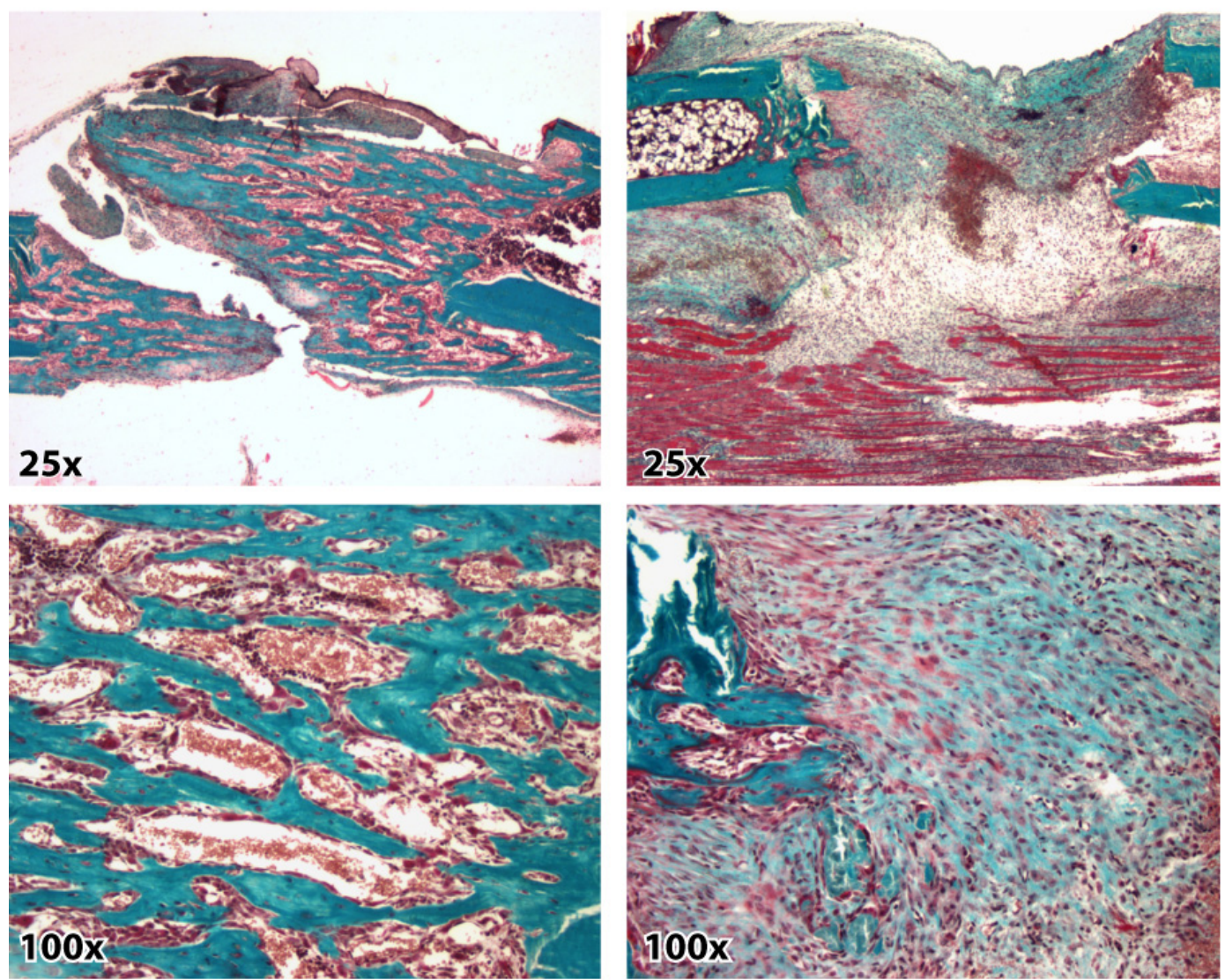

WT

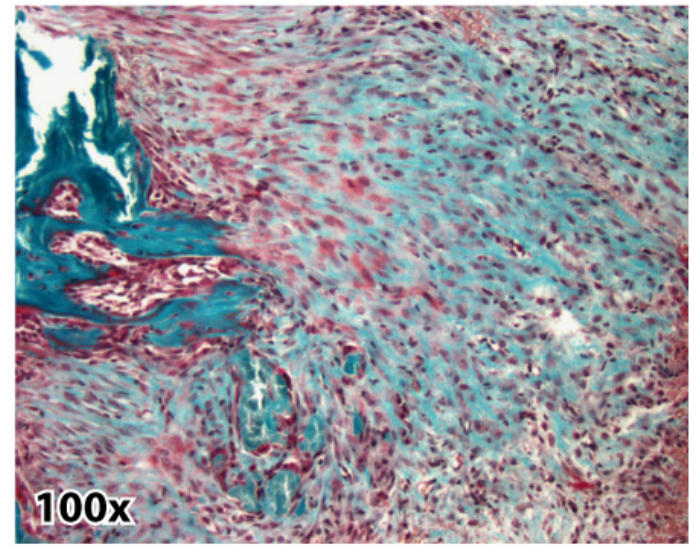

Het

Figure 10 No Mineralization Was Detected in the Distracted Samples of Heterozygous BMP2 ${ }^{\mathrm{fl} /+ \text { cre }}$ Mice at 17 Days Post-Osteotomy.

MMA embedded tibial sections of wild-type and heterozygous mice were Goldner Trichome stained. At 17 days, end of distraction phase, bone formation was initiated within the distracted gap of the wild-type $\mathrm{BMP}^{\mathrm{fl} / \mathrm{+}}$ samples. At 100x, osteoblasts depositing osteoid are visible within the wild-type sections. However, the heterozygous $\mathrm{BMP}^{\mathrm{fl} /+}$ cre mice contained mostly fibrocartilaginous cells and lacked new bone formation. 

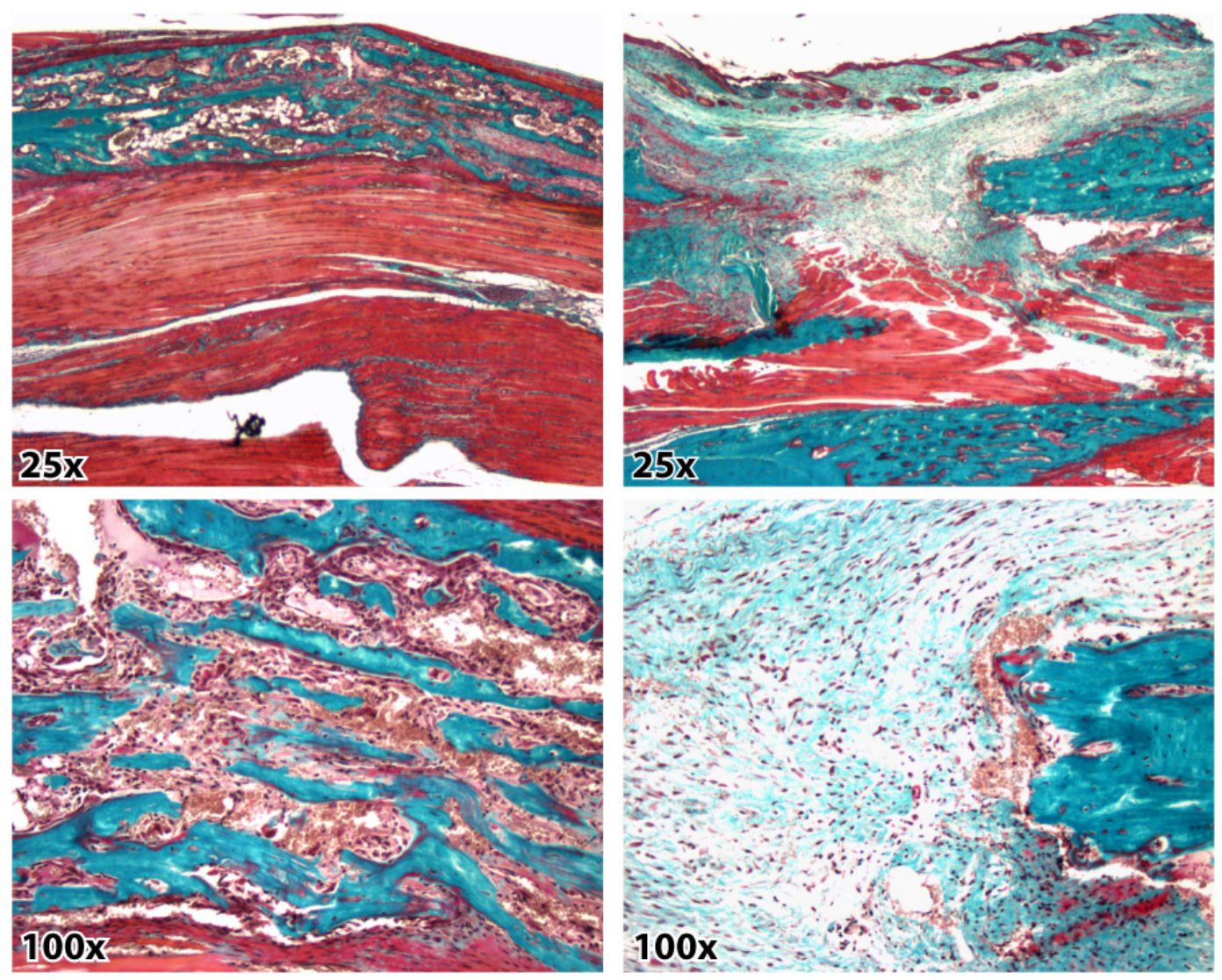

WT

\section{Het}

Figure 11 At 34 Days Post-Osteotomy, the Distracted Zone of Heterozygous BMP2 $^{\mathrm{fl} /+}$ cre Mice Still Lacked Mineralization.

MMA embedded tibial sections of wild-type and heterozygous mice were Goldner Trichome stained. At 34 days, the control BMP2 $2^{\mathrm{fl} /+}$ sections exhibited strong mineralization, indicated by large areas of calcified tissue in the distracted zone. During early consolidation, the BMP2 $2^{\mathrm{f} /+}$ cre samples lacked strong bone formation, as the stained sections mostly contained fibrous tissue with no mineralization. 


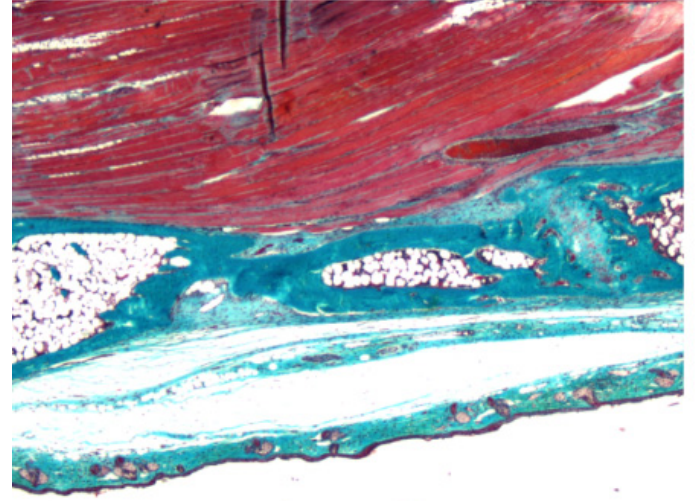

$25 x$

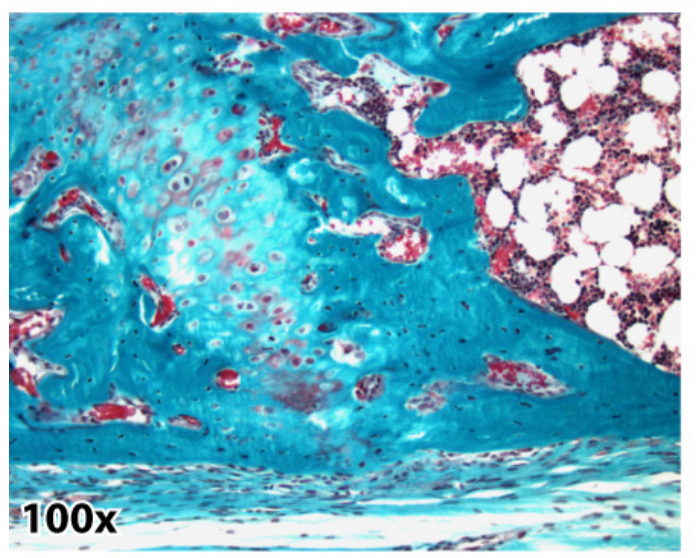

WT
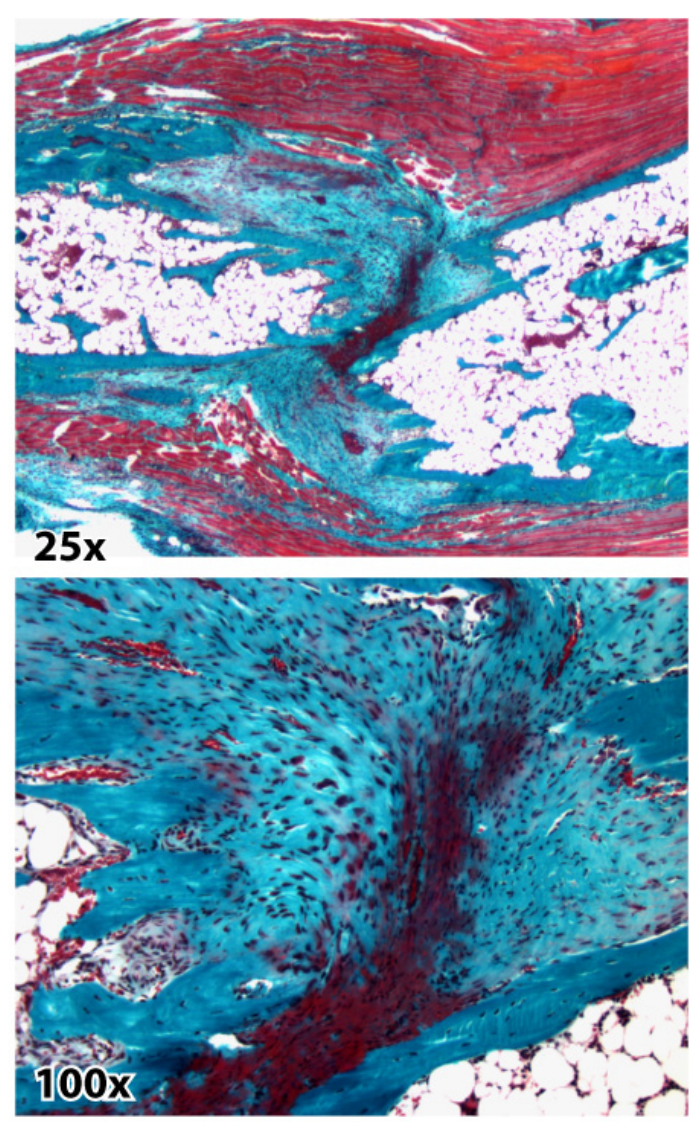

Het

Figure 12 Improper Bone Healing Was Observed in Distracted BMP2 ${ }^{\mathrm{f} /}+$ cre Mice at 51 days Post-Osteotomy.

MMA embedded tibial sections of wild-type and heterozygous mice were Goldner Trichome stained. At 51 days, end of consolidation, the wild-type mice revealed complete consolidation of the fractured gap with calcified tissue. Furthermore, the heterozygous $\mathrm{BMP}^{\mathrm{fl} /}+\mathrm{cre}$ sections contained partial fusion of the distracted gap with moderate levels of mineralization. 


\section{6-Real Time Quantitative PCR Results}

RNA collected from wild-type and heterozygous mice at 11, 17, $34 \& 51$

days post-surgery was reverse transcribed for RT-qPCR analysis (Table 3). Gene expression in distracted tibial samples was monitored using BMP signaling pathway, osteoblastic and chondrogenic markers. BMP signaling pathway markers included BMP2, BMP3, BMP4, BMP6, BMP7, BMPR1A, BMPR1B, BMPR2, Gremlin, Chordin, SMAD1, SMAD2, SMAD3, SMAD4, SMAD5, SMAD6, SMAD7 \& SMAD9. Osteoblastic markers comprised of Runx2, OSX, OCN \& ATF4 and chondrogenic markers included Colla1 \& Sox9. RT-qPCR analysis revealed that there was no significant difference in gene expression for any of the osteogenic markers between wild-type and heterozygous samples. Eight of the twenty-four studied genes (BMP3, BMP6, BMPR1b, BMPR2, SMAD7, SMAD9, Runx2 \& Sox9) could not be analyzed for statistical significance because three distracted samples provided low-yield RNA. Groups containing these samples were omitted from the study to see if there were any undetected changes in gene expression levels between BMP2 ${ }^{f l /+}$ mice and BMP2 $f l / c r e$ mice. Subsequently, there was still no changes gene expression detected between the control and the heterozygous mice during any of the time points. 
Table 3: No Difference in the Expression of BMP Signaling Pathway Members Was Detected Between Wild-Type \& Heterozygous BMP2 Deficient Mice.

\begin{tabular}{|l|c|}
\hline \multicolumn{1}{|c|}{ Gene } & $\begin{array}{c}\text { Relative } \\
\text { Expression }\end{array}$ \\
\hline BMP Signaling Pathway Markers & \\
BMP Ligands & \\
BMP 2 & - \\
BMP 4 & - \\
BMP 6* & UD. \\
BMP7 & - \\
\hline BMP Receptors & \\
BMPR1A & - \\
BMPR1B* & UD. \\
BMPR2* & UD. \\
\hline BMPInhibitors & \\
Gremlin & - \\
Chordin & - \\
BMP3* & UD. \\
\hline Intracellular BMP Signaling Members & \\
SMAD1 & - \\
SMAD2 & - \\
SMAD3 & - \\
SMAD4 & - \\
SMAD5 & - \\
SMAD6 & - \\
SMAD7* & - \\
SMAD9* & UD. \\
\hline Osteoblastic Markers & UD. \\
Runx2 * & \\
OSX & UD. \\
OCN & - \\
ATF4 & - \\
\hline Chondrogenic Markers & - \\
Col1a1 & UD. \\
Sox9* & \\
\hline
\end{tabular}

-; no change in relative expr ession between distracted wild-type and mutant populations.

UD. ; gene expression could not be analyzed for statistical significance because of samples had low-yield RNA.

Reverse transcribed RNA was collected from control BMP2 $2^{\mathrm{fl} /+}$ mice and heterozygous $\mathrm{BMP} 2^{\mathrm{fl} /+} \mathrm{cre}$ mice at 11 days (mid-distraction phase), 17 days (end of distraction phase), 34 days (mid-consolidation phase) \& 51 days (end of consolidation phase) post-surgery ( $n=3$ mice per time point) and analyzed using RTqPCR. The expression of BMP signaling pathway genes, osteoblastic and chondrogenic genes were monitored in the distracted gap over the various time points. RT-qPCR analysis revealed there was no difference in gene expression for the twenty-four BMP signaling pathway members between control and heterozygous populations. Eight of the twenty-four studied genes (BMP3, BMP6, BMPR1b, BMPR2, SMAD7, SMAD9, Runx2 \& Sox9) could not be analyzed for statistical significance because of low-yield RNA (denoted by UD., undetectable). 


\section{7-Biomechanical Testing Results}

Distracted samples collected from wild-type and heterozygous mice at 51 days were analyzed using the three-point bending test (Fig. 13). Results showed that there were no significant differences in the biomechanical properties between the control and heterozygous groups. However, there was a decrease in stiffness and increase in ultimate displacement observed in the heterozygotes compared to the wild-type mice, corresponding to the weaker partially consolidated bone of the heterozygous mice. 

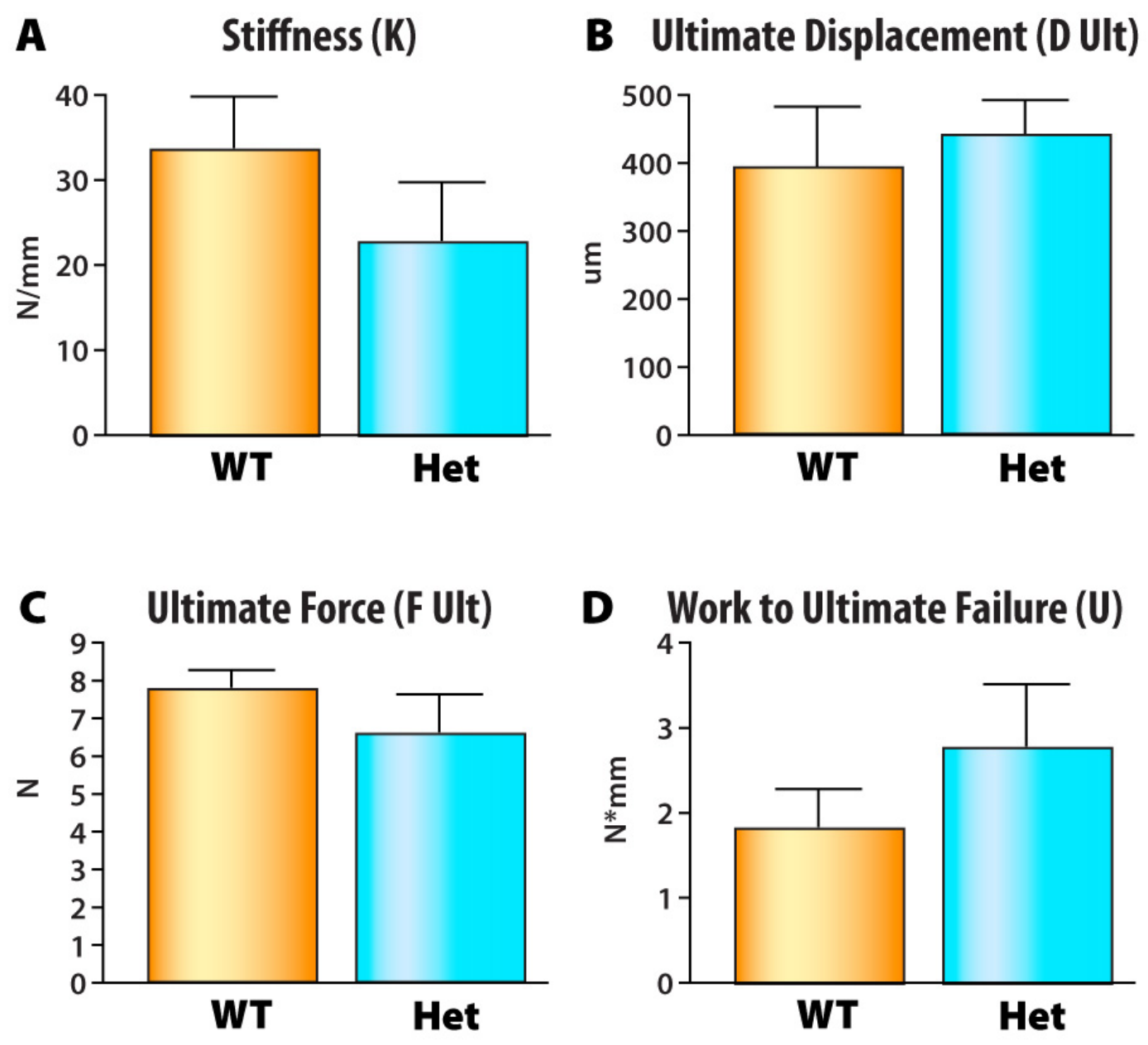

Figure 13 Biomechanical Testing Results of Distracted Wild-Type \& Heterozygous BMP2 Deficient Mice at 51 days Post-Osteotomy.

Biomechanical testing, using the three-point bending test, was performed on distracted wild-type and heterozygous samples collected at the end of consolidation phase, 51 days post-osteotomy $(n=3)$. There was no significant difference observed in stiffness (A), ultimate displacement (B), ultimate force (C) and work to ultimate failure (D) between the control BMP2 $\mathrm{fl} /+$ samples and heterozygous BMP2 $\mathrm{fl} /+\mathrm{cre}$ samples. However a decrease in stiffness and increase in ultimate displacement supports the weaker callus formation observed in the heterozygous mice at the end of consolidation, compared to the wildtype controls. 


\section{0-DISCUSSION}

Different methods have been studied to accelerate the consolidation phase of DO. Particularly, the application of exogenous BMP2 and BMP7 seems to be very promising (Rengachary. 2002). One main concern is that large pharmacological doses of exogenous BMPs would be required in order to obtain clinically significant results. Furthermore, the use of such large doses of BMPs may induce unknown long term side effects (Haque et al., 2008). An alternative approach to the application of exogenous BMPs would be the manipulation the endogenous BMP pathway in order to upregulate BMP expression or other possible downstream gene targets that may somehow accelerate the bone healing process during DO. Since the physiological role of BMPs during DO is unclear, the purpose of this study was to gain a better understanding of the physiological role of endogenous BMPs during DO.

In the first of part of this thesis, we examined the expression patterns of BMP pathway members during DO in wild-type mice. Distraction osteogenesis was performed on the right tibia of eighty wild-type C57B16/J mice. Mice underwent 5 days of latency, 12 days of distraction (distraction rate: $0.2 \mathrm{~mm} / 12$ and 34 days. Distracted tibial samples were collected at 5, 11, 17, 34 \& 51 days post-surgery. Samples were analyzed using various techniques including $\mu \mathrm{CT}$, radiology, immunohistochemistry, histology, Real Time PCR and western blot analysis. Results for this study were previously published (Haque et al., 2008). 
I performed a western blot analysis of the distracted wild-type mice. These results (see fig. 5 in Appendix) showed that SMAD and upstream p38 MAPK \& ERK 1/2 pathways are activated during the process of DO.

Furthermore, peak levels of SMAD1 expression during early consolidation confirmed the direct activity of BMP signaling to target cells via intracellular SMAD signaling. Moreover, p38 MAPK and ERK 1/2 expression corresponded with peak BMP ligand expression during the distraction phase of DO. Whether the increased expression of upstream signaling members during the distraction phase of DO is dependent on BMP signaling or the interaction of other growth factors requires further investigation. Thus, results from this study demonstrated that BMP family members are expressed during different phases of DO (Haque et al., 2008).

In this study, we initially performed DO on conditional BMP2 null (BMP2 flfl cre ) mice but these mice were too weak to withstand DO as they suffered from spontaneous fracture formation during surgery. Similar findings were made by Tsuji and colleagues who demonstrated that by 13 to 23 weeks of age, the BMP2 flfl cre mice developed forearm, hind limb and bilateral fractures in sites with low bone mineral density, while the heterozygous BMP2 $2^{f / /++c r e}$ mice exhibited intermediate bone mass and impaired fracture repair (Tsuji et al., 2006). Thus, instead of operating on the homozygous BMP2 ${ }^{\text {flfl cre }}$ mice, we analyzed the effects of DO on heterozygous BMP2 ${ }^{f / l+c r e}$ mice. While performing surgeries, we noted that the heterozygous mice had a higher surgical success rate than the 
wild-type controls. This may be accounted for by the fact we spent more time operating on the heterozygous mice to avoid pin site fractures as the bones of the heterozygous mice were more fragile than their wild-type littermates. We then collected distracted tibial samples from these mice at $11,17,34 \& 51$ days postsurgery and analyzed the samples using $\mu \mathrm{CT}$, Faxitron x-ray, immunohistochemistry, Goldner-Trichrome staining, Real Time PCR and biomechanical testing.

In order to verify that the heterozygous mice contained reduced BMP2 expression, we performed RT-qPCR analysis of BMP2 expression in all three genotypes of the conditional BMP2 knockout mice. These RT-qPCR results revealed a gene-dosage dependant reduction in BMP2 expression in the conditional BMP2 knockout mice. Similarly, Tsuji and colleagues reported that gene-dosage dependant expression of BMP2 exists in a fracture healing model using conditional BMP2 ablated mice (Tsuji et al., 2006). Hence, these results confirmed that there is a gene-dosage effect for BMP2 expression in the heterozygous mice. This conclusion was firmed up when BMP2 protein expression was assessed by immunodetection in the distracted limbs (Fig. 9).

Further analysis using $\mu \mathrm{CT}$ and Faxitron x-ray showed that a gene-dosage dependant BMP2 reduction in the heterozygous mice resulted in a delay in bone healing during DO compared to the controls. This observation was supported by a statistically significant decrease in trabecular number and increase in trabecular separation at 51 days in the heterozygous mice compared to their wild-type 
littermates. However, these $\mu \mathrm{CT}$ and Faxitron $\mathrm{x}$-ray results were somewhat variable: for example, histological images of the 17 day control (Fig.9) did not correspond with the $\mu \mathrm{CT}$ and Faxitron x-ray images of the 17 day control (Fig.7). In this case, the histological images of the 17 day control seemed to contain more bone formation than the $\mu \mathrm{CT}$ and Faxitron x-ray images of the 17 control. Incomplete penetrance of cre-mediated Bmp2 excision or gender differences are possible factors that may account for such variability amongst samples for each time point.

Immunohistochemical staining in chondrocytes showed a decrease in BMP2, BMP7, BMPR1a, ActR1 \& ActR2b expression at 34 days post-osteotomy. This decrease in BMP ligand/receptor expression at 34 days could possibly explain the reason why poor bone formation was observed in the heterozygous mice throughout the consolidation phase; reduced BMP/BMPR expression may result in decreased bone formation at the distracted site. At 51 days post-surgery, we observed there was an upregulation of BMP7 and ActR2b expression. Whether this upregulation of BMP7 expression at 51 days was a compensatory mechanism triggered by decreased BMP2 levels at 34 days remains to be determined. Studies have shown that BMP7 uses ActR2 as its type II receptor (Shimizu et al., 2006). Thus, there is a possibility that the increase in ActR2b expression observed at 51 days in the heterozygous mice may have been stimulated by the increased BMP7 levels observed at the same time point. Interestingly, the upregulation of BMP7 expression could not compensate for the decreased BMP2 expression in the heterozygous mice. 
Histological examination of heterozygous distracted samples further confirmed that the heterozygous mice contained impaired bone repair compared to the wild-type mice. The histological images clearly showed that the distracted zones of the BMP2 ${ }^{f /+c r e}$ mice appeared to consolidate more slowly than the control BMP2 ${ }^{f l+}$ mice.

Our Real Time PCR data showed no changes in the relative expression of the twenty-four studied osteogenic markers during any of the four time points between wild-type and heterozygous distracted mice. Possible explanations for these results could be RNA degradation, loss of RNA during sample handling or contamination of sample with other cell types that are not specific to the distracted zone. Lastly, biomechanical results also supported the finding that the heterozygous mice have impaired bone formation during DO as the 51 day heterozygous samples showed a decrease in stiffness and increase in ultimate displacement.

Although we observed a delay in bone consolidation in the conditional heterozygous mice, a question to address is whether this prolonged bone formation in the heterozygous mice is initiated during late consolidation or at an earlier time point. Possible methods to test this theory include increasing the sample size of mice per time point, harvesting these samples at more frequent time points in between the distraction and early consolidation phase of DO and performing dynamic histomorphometry analysis using the tetracycline double 
labeling technique to study mineralization patterns in the heterozygous and wildtype mice.

One of the principal concerns of the current study is the existence of variation between samples, as previously mentioned. Gender-induced variation can easily be addressed by studying same gender cohorts. Variation caused by the incomplete penetrance of cre-mediated Bmp2 excision could be remedied by performing DO on conventional heterozygous BMP2 knockout mice to see if these mice also contain prolonged bone consolidation. Unlike the homozygous mutants that die early postnatally, the heterozygous mutants are phenotypically normal (Zhang. 1996). It would also be interesting to study the effects of DO using chondrogenic tissue-specific BMP2 knockout mice as our immunohistochemical results indicated that mostly chondrocytes stained positively for the selected BMP members. Such mice can me generated by crossing mice containing a floxed Bmp2 allele with Col2::cre transgenic mice (Terpstra et al., 2003).

The results of this study clearly demonstrate that when distraction osteogenesis is performed on heterozygous mice with a gene-dosage dependent reduction in BMP2 expression in the limbs, these heterozygous mice exhibit a prolonged bone consolidation compared to the controls. Previously, Tsuji and colleagues reported that conditional BMP2 deficient mice had impaired bone formation in a similar model of fracture healing (Tsuji et al., 2006). Even though, both models of DO and fracture healing share similarities, there are significant 
differences that exist in the temporal expression of molecular factors unique to each model (Al-Aql et al., 2008). Most importantly, this study suggests that BMP2 does exert a physiological role during DO and that the manipulation of the endogenous BMP pathway may be a potential alternative for the treatment of accelerating the consolidation phase of DO. Therefore, future studies should attempt to study the effects of manipulating the endogenous BMP pathway during DO. 


\section{0-REFERENCES}

1. Al-Aql ZS, Alagl AS, Graves DT, Gerstenfeld LC, Einhorn TA. Molecular Mechanisms Controlling Bone Formation during Fracture Healing and Distraction Osteogenesis-The cellular and molecular mechanisms. Journal of Dental Research. 2008;87(2): 107-18.

2. Amir LR, Jovanovic A, Perdijk FBT, Toyosawa S, Everts V, Bronckers A. Immunolocalization of Sibling and RUNX2 Proteins During Vertical Distraction Osteogenesis in the Human Mandible. Journal of Histochemistry and Cytochemistry. 2007;55(11): 1095.

3. Aronson J, Harrison BH, Stewart CL, Harp Jr JH. The histology of distraction osteogenesis using different external fixators. Clin Orthop Relat Res. 1989;241: 106-16.

4. Balemans W, Van Hul W. Extracellular Regulation of BMP Signaling in Vertebrates: A Cocktail of Modulators. Developmental Biology. 2002;250(2): 231-50.

5. Bandyopadhyay A, Tsuji K, Cox K, Harfe BD, Rosen V, Tabin CJ. Genetic analysis of the roles of BMP2, BMP4, and BMP7 in limb patterning and skeletogenesis. PLoS Genet. 2006;2(12): e216. 
6. Barnes GL, Kostenuik PJ, Gerstenfeld LC, Einhorn TA. Growth Factor Regulation of Fracture Repair. Journal of Bone and Mineral Research. 1999;14(11): 1805-15.

7. Biase PD, Capanna R. Clinical applications of BMPs. Injury. 2005;36(3S): 4346.

8. Bogdanovich S, Perkins KJ, Krag TOB, Whittemore LA, Khurana TS. Myostatin propeptide-mediated amelioration of dystrophic pathophysiology. FASEB. 2005;19(6): 543-49.

9. Borovecki F, Pecina-Slaus N, Vukicevic S. Biological mechanisms of bone and cartilage remodelling_-genomic perspective. International Orthopaedics. 2007;31(6): 799-805.

10. Brown MA, Zhao Q, Baker KA, Naik C, Chen C, Pukac L, et al. Crystal Structure of BMP-9 and Functional Interactions with Pro-region and Receptors. Journal of Biological Chemistry. 2005;280(26): 25111.

11. Canalis E, Economides AN, Gazzerro E. Bone Morphogenetic Proteins, Their Antagonists, and the Skeleton. Endocrine Reviews. 2003;24(2): 218-35.

12. Canalis E, McCarthy TL, Centrella M. Growth Factors and Cytokines in Bone Cell Metabolism. Annual Reviews in Medicine. 1991;42(1): 17-24. 
13. Cao X, Chen D. The BMP signaling and in vivo bone formation. Gene. 2005;357(1): 1-8.

14. Carano RAD, Filvaroff EH. Angiogenesis and bone repair. Drug Discovery Today. 2003;8(21): 980-89.

15. Chan MC, Nguyen PH, Davis BN, Ohoka N, Hayashi H, Du K, et al. A Novel Regulatory Mechanism of the Bone Morphogenetic Protein (BMP) Signaling Pathway Involving the Carboxyl-Terminal Tail Domain of BMP Type II Receptor? Molecular and Cellular Biology. 2007;27(16): 5776-89.

16. Chang F, Mishima H, Ishii T, Yanai T, Akaogi H, Sakai S, et al. Stimulation of EP4 receptor enhanced bone consolidation during distraction osteogenesis. Journal of Orthopaedic Research. 2007;25(2): 221.

17. Chen B, Lin H, Wang J, Zhao Y, Wang B, Zhao W, et al. Homogeneous osteogenesis and bone regeneration by demineralized bone matrix loading with collagen-targeting bone morphogenetic protein-2. Biomaterials. 2007;28(6): 1027-35.

18. Cho BC, Chung HY, Lee DG, Yang JD, Park JW, Roh KH, et al. The Effect of Chitosan Bead Encapsulating Calcium Sulfate as an Injectable Bone Substitute on Consolidation in the Mandibular Distraction Osteogenesis of 
a Dog Model. Journal of Oral and Maxillofacial Surgery. 2005;63(12): 1753-64.

19. Choi IH, Chung CY, Cho TJ, Yoo WJ. Angiogenesis and Mineralization During Distraction Osteogenesis. Journal of Korean Medical Science. 2002;17(4): 435-47.

20. Claes L, RÜTer A, Mayr E. Low-intensity ultrasound enhances maturation of callus after segmental transport. Clinical orthopaedics and related research. 2005(430): 189-94.

21. Claes L, Willie B. The enhancement of bone regeneration by ultrasound. Progress in Biophysics and Molecular Biology. 2007;93(1-3): 384-98.

22. DeCoster TA, Gehlert RJ, Mikola EA, Pirela-Cruz MA. Management of Posttraumatic Segmental Bone Defects. Journal of the American Academy of Orthopaedic Surgeons. 2004;12(1): 28-38.

23. Delloye C, Delefortrie G, Coutelier L, Vincent A. Bone regenerate formation in cortical bone during distraction lengthening. An experimental study. Clin Orthop Relat Res. 1990;250: 34-42.

24. Derynck R, Zhang YE. Smad-dependent and Smad-independent pathways in TGF-beta family signalling. Nature. 2003;425(6958): 577-84. 
25. Ducy P, Karsenty G. Genetic control of cell differentiation in the skeleton. Current Opinion in Cell Biology. 1998;10(5): 614-19.

26. Eberson CP, Hogan KA, Moore DC, Ehrlich MG. Effect of low-intensity ultrasound stimulation on consolidation of the regenerate zone in a rat model of distraction osteogenesis. Journal of pediatric orthopedics. 2003;23(1): 46-51.

27. Einhorn TA. Clinical Applications of Recombinant Human BMPs: Early Experience and Future Development. Journal of Bone \& Joint Surgery. 2003;85(90003): 82-88.

28. Farhadieh RD, Gianoutsos MP, Yu Y, Walsh WR. The Role of Bone Morphogenetic Proteins BMP-2 and BMP-4 and Their Related Postreceptor Signaling System (Smads) in Distraction Osteogenesis of the Mandible. Journal of Craniofacial Surgery. 2004;15(5): 714.

29. Greenwald JA, Luchs JS, Mehrara BJ, Spector JA, Mackool RJ, McCarthy JG, et al. Pumping the regenerate: An evaluation of oscillating distraction osteogenesis in the rodent mandible. Annals of plastic surgery. 2000;44(5): 516-21. 
30. Groppe J, Greenwald J, Wiater E, Rodriguez-Leon J, Economides AN, Kwiatkowski W, et al. Structural Basis of BMP Signaling Inhibition by , a Novel Twelve-Membered Cysteine Knot Protein. Journal of Bone \& Joint Surgery. 2003;85(90003): 52-58.

31. Hamdy RC, Amako M, Beckman L, Kawaguchi M, Rauch F, Lauzier D, et al. Effects of osteogenic protein-1 on distraction osteogenesis in rabbits. Bone. 2003;33(2): 248-55.

32. Haque T, Hamade F, Alam N, Kotsiopriftis M, Lauzier D, St-Arnaud R, et al. Characterizing the BMP pathway in a wild type mouse model of distraction osteogenesis. Bone. 2008;42(6): 1144-53.

33. Haque T, Mandu-Hrit M, Rauch F, Lauzier D, Tabrizian M, Hamdy RC. Immunohistochemical Localization of Bone Morphogenetic Proteinsignaling Smads during Long-bone Distraction Osteogenesis. Journal of Histochemistry and Cytochemistry. 2006;54(4): 407.

34. Hartmann C. Skeletal Development-Wnts Are in Control. Molecules and Cells. 2007;24(2): 177.

35. Heckman JD. Acceleration of tibial fracture-healing by non-invasive, lowintensity pulsed ultrasound. Journal of Bone \& Joint Surgery. 1994;76(1): 26-34. 
36. Hillger F, Herr G, Rudolph R, Schwarz E. Biophysical Comparison of BMP2, ProBMP-2, and the Free Pro-peptide Reveals Stabilization of the Propeptide by the Mature Growth Factor. Journal of Biological Chemistry. 2005;280(15): 14974.

37. Hu J, Qi MC, Zou SJ, Li JH, Luo E. Callus formation enhanced by BMP-7 ex vivo gene therapy during distraction osteogenesis in rats. Journal of Orthopaedic Research. 2007;25(2): 241.

38. Ilizarov G. The tension-stress effect on the genesis and growth of tissues: Part II. The influence of the rate and frequency of distraction. Clinical orthopaedics and related research. 1989;239: 263-85.

39. Ilizarov G. The tension-stress effect on the genesis and growth of tissues. I: The infleunces of stability of fixation and soft-tissue preservation. Clinical orthopaedics and related research. 1989(238): 249-81.

40. Ilizarov G. Operative Principles of Ilizarov. Italy: A.S.A.M.I. Group; 1990. 3-8.

41. Ilizarov GA. Clinical application of the tension-stress effect for limb lengthening. Clinical orthopaedics and related research. 1990(250): 8-26. 
42. Jämsä T, Jalovaara P, Peng Z, Väänänen HK, Tuukkanen J. Comparison of three-point bending test and peripheral quantitative computed tomography analysis in the evaluation of the strength of mouse femur and tibia. Bone. 1998;23(2): 155-61.

43. Kavsak P, Rasmussen RK, Causing CG, Bonni S, Zhu H, Thomsen GH, et al. Smad7 Binds to Smurf2 to Form an E3 Ubiquitin Ligase that Targets the TGFß Receptor for Degradation. Molecular Cell. 2000;6(6): 1365-75.

44. Khanal A, Yoshioka I, Tominaga K, Furuta N, Habu M, Fukuda J. The BMP signaling and its Smads in mandibular distraction osteogenesis. Oral Diseases. 2008;14(4): 347.

45. Kim UK, Chung IK, Lee KH, Swift JQ, Seong WJ, Ko CC. Bone Regeneration in Mandibular Distraction Osteogenesis Combined With Compression Stimulation. Journal of Oral and Maxillofacial Surgery. 2006;64(10): 1498-505.

46. Kirker-Head CA. Potential applications and delivery strategies for bone morphogenetic proteins. Advanced Drug Delivery Reviews. 2000;43(1): $65-92$.

47. Kitoh H, Kitakoji T, Tsuchiya H, Katoh M, Ishiguro N. Transplantation of 
culture expanded bone marrow cells and platelet rich plasma in distraction osteogenesis of the long bones. Bone. 2007;40(2): 522-28.

48. Kitoh H, Kitakoji T, Tsuchiya H, Mitsuyama H, Nakamura H, Katoh M, et al. Transplantation of marrow-derived mesenchymal stem cells and plateletrich plasma during distraction osteogenesis - a preliminary result of three cases. Bone. 2004;35(4): 892-98.

49. Kojimoto H, Yasui N, Goto T, Matsuda S, Shimomura Y. Bone Lengthening In Rabbits By Callus Distraction. Journal of Bone \& Joint Surgery, British Volume. 1988(70-B): 543-9.

50. Komori T, Yagi H, Nomura S, Yamaguchi A, Sasaki K, Deguchi K, et al. Targeted disruption of Cbfa1 results in a complete lack of bone formation owing to maturational arrest of osteoblasts. Cell. 1997;89(5): 755-64.

51. Kosher RA. Collagen gene expression during limb cartilage differentiation. The Journal of Cell Biology. 1986;102(4): 1151-56.

52. Leppänen OV, Sievänen H, Järvinen TLN. Biomechanical testing in experimental bone interventions-May the power be with you. Journal of Biomechanics. 2008.

53. Li G, Bouxsein ML, Luppen C, Li XJ, Wood M, Seeherman HJ, et al. Bone 
consolidation is enhanced by rhBMP-2 in a rabbit model of distraction osteogenesis. J Orthop Res. 2002;20(4): 779-88.

54. Lieberman JR, Daluiski A, Einhorn TA. The Role of Growth Factors in the Repair of Bone Biology and Clinical Applications. Journal of Bone \& Joint Surgery. 2002;84(6): 1032-44.

55. Ma L, Martin JF. Generation of a Bmp2 conditional null allele. Genesis. 2005;42(3): 203-06.

56. Malizos KN, Hantes ME, Protopappas V, Papachristos A. Low-intensity pulsed ultrasound for bone healing: An overview. Injury. 2006;37(1S): 5662.

57. Mandu-Hrit M, Haque T, Lauzier D, Kotsiopriftis M, Rauch F, Tabrizian M, et al. Early injection of OP-1 during distraction osteogenesis accelerates new bone formation in rabbits. Growth Factors. 2006;24(3): 172-83.

58. McGuigan FE, Larzenius E, Callreus M, Gerdhem P, Luthman H, Åkesson K. Variation in the BMP2 Gene: Bone Mineral Density and Ultrasound in Young Adult and Elderly Women. Calcified Tissue International. 2007;81(4): 254-62.

59. McKibbin B. The biology of fracture healing in long bones. Journal of Bone 
\& Joint Surgery, British Volume. 1978;60(2): 150-62.

60. Minina E, Kreschel C, Naski MC, Ornitz DM, Vortkamp A. Interaction of FGF, Ihh/Pthlh, and BMP Signaling Integrates Chondrocyte Proliferation and Hypertrophic Differentiation. Developmental Cell. 2002;3(3): 439-49.

61. Miyazono K. TGF-ß signaling by Smad proteins. Cytokine and Growth Factor Reviews. 2000;11(1-2): 15-22.

62. Mizumoto Y, Moseley T, Drews M, CooperIii VN, Reddi AH. Acceleration of Regenerate Ossification During Distraction Osteogenesis with Recombinant Human Bone Morphogenetic Protein-7. Journal of Bone \& Joint Surgery. 2003;85(90003): 124-30.

63. Nunotani Y, Abe M, Shirai H, Otsuka H. Efficacy of rhBMP-2 during distraction osteogenesis. J Orthop Sci. 2005;10(5): 529-33.

64. Onishi T, Ishidou Y, Nagamine T, Yone K, Imamura T, Kato M, et al. Distinct and Overlapping Patterns of Localization of Bone Morphogenetic Protein (BMP) Family Members and a BMP Type II Receptor During Fracture Healing in Rats. Bone. 1998;22(6): 605-12.

65. Ornitz DM, Marie PJ. FGF signaling pathways in endochondral and 
intramembranous bone development and human genetic disease. Genes \& Development. 2002;16(12): 1446-65.

66. Otto F, Thornell AP, Crompton T, Denzel A, Gilmour KC, Rosewell IR, et al. Cbfa1, a Candidate Gene for Cleidocranial Dysplasia Syndrome, Is Essential for Osteoblast Differentiation and Bone Development. CELLCAMBRIDGE MA-. 1997;89: 765-71.

67. Paley D. Problems, obstacles, and complications of limb lengthening by the Ilizarov technique. Clin Orthop Relat Res. 1990;250: 81-104.

68. Provot S, Schipani E. Molecular mechanisms of endochondral bone development. Biochemical and Biophysical Research Communications. 2005;328(3): 658-65.

69. Rauch F, Lauzier D, Croteau S, Travers R, Glorieux FH, Hamdy R. Temporal and spatial expression of bone morphogenetic protein-2,-4, and-7 during distraction osteogenesis in rabbits. Bone. 2000;27(3): 453-59.

70. Rengachary S. Bone morphogenetic proteins: basic concepts. Neurosurgical Focus. 2002;13(6): 1-6.

71. Riggs BL, Parfitt AM. Drugs used to treat osteoporosis: the critical need for a 
uniform nomenclature based on their action on bone remodeling. J Bone Miner Res. 2005;20(2): 177-84.

72. Robert B. Bone morphogenetic protein signaling in limb outgrowth and patterning. Development, Growth and Differentiation. 2007;49(6): 455-68.

73. Rosen V. BMP and BMP Inhibitors in Bone. Annals of the New York Academy of Sciences. 2006;1068(1 Skeletal Development and Remodeling in Health, Disease, and Aging): 19-25.

74. Rosen V, Cox K, Hattersley G. Principles of Bone Biology. San Diego, CA: Academic Press; 1996. 661-67

75. Sakurakichi K, Tsuchiya H, Uehara K, Yamashiro T, Tomita K, Azuma Y. Effects of timing of low-intensity pulsed ultrasound on distraction osteogenesis. Journal of Orthopaedic Research. 2004;22(2): 395-403.

76. Schipani E. Conditional gene inactivation using cre recombinase. Calcified Tissue International. 2002;71(2): 100-02.

77. Schwechter EM. Limb Lengthening and Reconstruction Surgery; 2007.

78. Seeherman HJ, Wozney JM, Simpson H. Bone consolidation is enhanced by 
rhBMP-2 in a rabbit model of distraction osteogenesis. Journal of Orthopaedic Research. 2002;20: 779-88.

79. Shimazaki A, Inui K, Azuma Y, Nishimura N, Yamano Y. Low-intensity pulsed ultrasound accelerates bone maturation in distraction osteogenesis in rabbits. Journal of Bone \& Joint Surgery, British Volume. 2000;82(7): 1077-82.

80. Shimizu T, Jayawardana B, Nishimoto H, Kaneko E, Tetsuka M, Miyamoto A. Involvement of the bone morphogenetic protein/receptor system during follicle development in the bovine ovary: Hormonal regulation of the expression of bone morphogenetic protein 7 (BMP-7) and its receptors (ActRII and ALK-2). Molecular and Cellular Endocrinology. 2006;249(12): $78-83$.

81. Takahashi M, Yukata K, Matsui Y, Abbaspour A, Takata S, Yasui N. Bisphosphonate modulates morphological and mechanical properties in distraction osteogenesis through inhibition of bone resorption. Bone. 2006;39(3): 573-81.

82. Takamine Y, Tsuchiya H, Kitakoji T, Kurita K, Ono Y, Ohshima Y, et al. Distraction osteogenesis enhanced by osteoblastlike cells and collagen gel. Clinical orthopaedics and related research. 2002(399): 240-46. 
83. Tay BKB, Le AX, Gould SE, Helms JA. Histochemical and molecular analyses of distraction osteogenesis in a mouse model. Journal of Orthopaedic Research. 1998;16(5): 636-42.

84. Terpstra, L., J. Prud'homme, A. Arabian, S. Takeda, G. Karsenty, S. Dedhar, and R. St-Arnaud. 2003. Reduced chondrocyte proliferation and chondrodysplasia in mice lacking the Integrin-Linked Kinase (ILK) in chondrocytes. J. Cell Biol. 162: 139-148.

85. Thompson Z, Miclau T, Hu D, Helms JA. A model for intramembranous ossification during fracture healing. Journal of Orthopaedic Research. 2002;20(5): 1091-98.

86. Tsiridis E, Upadhyay N, Giannoudis P. Molecular aspects of fracture healing: Which are the important molecules? Injury. 2007;38(1S): 11-25.

87. Tsubota S, Tsuchiya H, Shinokawa Y, Tomita K, Minato H. Transplantation of osteoblast-like cells to the distracted callus in rabbits. Journal of Bone \& Joint Surgery, British Volume. 1999;81(1): 125-29.

88. Tsuji K, Bandyopadhyay A, Harfe BD, Cox K, Kakar S, Gerstenfeld L, et al. BMP2 activity, although dispensable for bone formation, is required for the initiation of fracture healing. Nature Genetics. 2006;38: 1424-29. 
89. Tsumaki N, Kakiuchi M, Sasaki J, Ochi T, Yoshikawa H. Low-Intensity Pulsed Ultrasound Accelerates Maturation of Callus in Patients Treated with Opening-Wedge High Tibial Osteotomy by Hemicallotasis. The Journal of Bone and Joint Surgery. 2004;86(11): 2399-405.

90. Urist MR. Bone: Formation by Autoinduction. American Association for the Advancement of Science. 1965;150(3698): 893-99.

91. Vaes BLT, Ducy P, Sijbers AM, Hendriks JMA, van Someren EP, de Jong NG, et al. Microarray analysis on Runx2-deficient mouse embryos reveals novel Runx2 functions and target genes during intramembranous and endochondral bone formation. Bone. 2006;39(4): 724-38.

92. von Bubnoff A, Cho KWY. Intracellular BMP Signaling Regulation in Vertebrates: Pathway or Network? Developmental Biology. 2001;239(1): $1-14$.

93. Wan M, Cao X. BMP signaling in skeletal development. Biochemical and Biophysical Research Communications. 2005;328(3): 651-57.

94. Weiss S, Baumgart R, Jochum M, Strasburger CJ, Bidlingmaier M. Systemic Regulation of Distraction Osteogenesis: A Cascade of Biochemical Factors. Journal of Bone and Mineral Research. 2002;17(7): 1280-89. 
95. Xiao YT, Xiang LX, Shao JZ. Bone morphogenetic protein. Biochemical and Biophysical Research Communications. 2007;362(3): 550-53.

96. Yasui N, Sato M, Ochi T, Kimura T, Kawahata H, Kitamura Y, et al. Three Modes of Ossification During Distraction Osteogenesis in The Rat. Journal of Bone \& Joint Surgery, British Volume. 1997;79(5): 824-30.

97. Yeung H, Lee S, Fung K, Leung K. Expression of basic fibroblast growth factor during distraction osteogenesis. Clin Orthop Relat Res. 2001;385: $219-29$.

98. Yonezawa H, Harada K, Ikebe T, Shinohara M, Enomoto S. Effect of recombinant human bone morphogenetic protein-2 (rhBMP-2) on bone consolidation on distraction osteogenesis: a preliminary study in rabbit mandibles. Journal of Cranio-Maxillofacial Surgery. 2006;34(5): 270-76.

99. Yu Y, Yang JL, Chapman-Sheath PJ, Walsh WR. TGF-, BMPs, and their signal transducing mediators, Smads, in rat fracture healing. J Biomed Mater Res. 2002;60: 392-97.

100. Zhang H. Mice deficient for BMP2 are nonviable and have defects in amnion/chorion and cardiac development. Development. 1996;122(10): 2977-86. 
101. Zhu H, Kavsak P, Abdollah S, Wrana JL, Thomsen GH. A SMAD ubiquitin ligase targets the BMP pathway and affects embryonic pattern formation. Nature(London). 1999;400(6745): 687-93. 


\section{0-APPENDIX}

\section{1- Western Blot Results}

For western blot analysis, protein was extracted from the distracted zone of tibial samples collected at 5, 11, 17, 34 and 51 days post-surgery. The protein samples were then probed with antibodies specific for SMAD independent signaling pathway members (P-ERK 1/2, ERK 1/2, P-p38 MAPK and p38 MAPK) and SMAD dependant signaling pathway members (P-SMAD 1 and SMAD 1). The ratio of phosphorylated to non-phosphorylated forms of SMAD-1, ERK 1/2 and p38 MAPK were graphed relative to the five time points. The PERK 1/2 / ERK 1/2 ratio showed a statistically significant increase in protein expression during the distraction phase, followed by a decrease in protein expression during the consolidation phase (Fig 5A). The P-p38 MAPK/ p38 MAPK results demonstrated a more varied pattern of protein expression: increased expression was observed during the distraction phase followed by a drop in protein levels during early consolidation and a rise in protein expression by late consolidation (Fig. 5B). P-SMAD-1/SMAD-1 results, although not statistically significant, exhibited an increase in protein expression during the consolidation phase (Fig. 5C). 

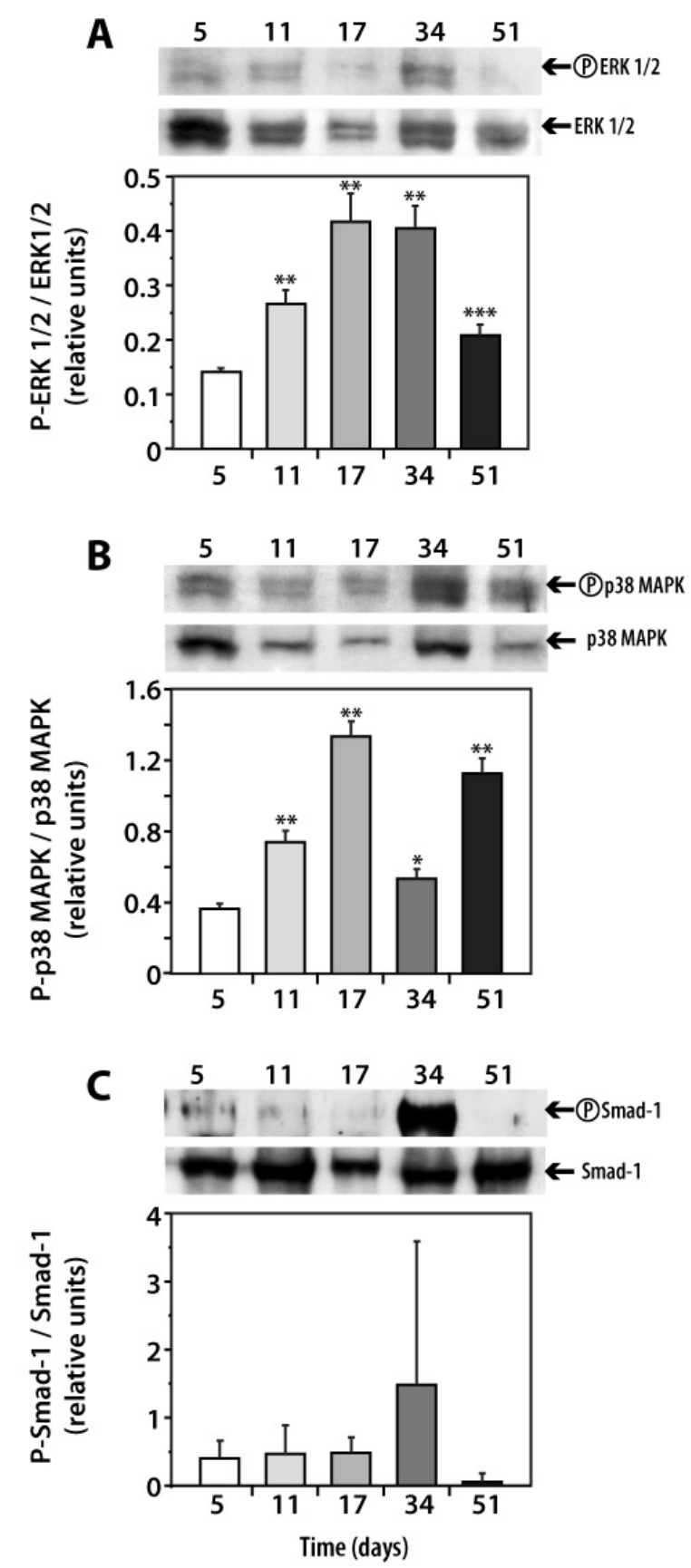

Figure 5 Western Blot of BMP Signaling in Wild-type Mouse Model of DO.

Protein was isolated from the distracted tibial samples from wild-type mice. The protein samples were probed with phosphorylated and non-phosphorylated forms of (A) ERK 1/2, (B) p38 MAPK and (C) SMAD-1. The ratio of phosphorylated to non-phosphorylated forms of BMP signaling members were graphed relative to the five time points. Increased ERK $1 / 2$ and p38 MAPK protein expression was observed during the distraction phase. SMAD-1 expression was elevated during the early consolidation period of DO. 


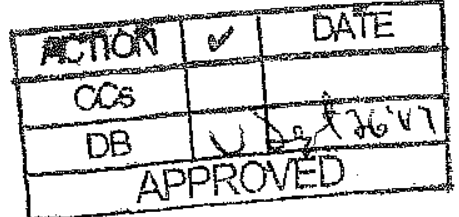

\section{McGill University Animal Care Committee RENEWAL of Animal Use Protocol}

unw.mcgill.ca/research/compliance/animal/forms/

For Office Use Only:

Protocol \#: $516:$

Approval end datekfity $31,900 \%$

Facility Committee: $\mathrm{CH}$

Renewal\#: $1^{\text {st }} 2^{\text {nd }}$
Principal Investigator:

Protocol Title:

Unit, Dept. \& Address:

\author{
For: $\quad$ Research $\square \quad$ Teaching $\square \quad$ project
}

Email: rhamdy@shriners.mcgill.ca

Dr. Reggie Hamdy (Co-PI with Dr. Rene St. Arnaud)

The role of Bone Morphogenetic Protein (BMP) in distraction osteogenesis
Protocol \# 5162

Category: D

Orthopaedics, Shriners Hospital for Children, 1529 Cedar Ave. Montreal QC, H3G 1A6

Funding source: Shriners

Start of Funding: Jan 2005

Phone: (514) 842-4464

Fax:

(514) $842-8664$

Emergency contact \#1+ work AND home phone \#s:

Emergency contact $\# 2+$ work AND home phone \#s:

End of Funding: $\quad \operatorname{Jan} 2008$

Norine Alam (514) 842-4464 ext 3316 (work), (514) 260-1088

Mia Esser (514) 842-4464 ext 3305 (work), (514) 684-7590 (home)

\section{Personnel and Qualifications}

List the names of the Principal Investigator and of all individuals who will be in contact with animals in this study and their employment classification (investigator, technician, research assistant, undergraduate/graduate student, fellow). Indicate if the Principal Investigator is not handling animals. If an undergraduate student is involved, the role of the student and the supervision received must be described. Training is mandatory for all personnel listed here. Refer to www.animalcare.mcgill.ca for details. Each person listed in this section must sign. (Space will expand as needed)

\begin{tabular}{|l|l|l|l|l|}
\hline \multirow{2}{*}{ Name } & \multirow{2}{*}{ Classification } & \multicolumn{2}{|c|}{ Animal Related Training Information } \\
UACC on-line & \multicolumn{2}{|c|}{$\begin{array}{c}\text { Workshops + others } \\
\text { Occupational } \\
\text { Health } \\
\text { Program * }\end{array}$} & $\begin{array}{c}\text { Signature } \\
\text { "Has read the } \\
\text { original } \\
\text { full protocol" }\end{array}$ \\
\hline Rene St-Arnaud & $\begin{array}{l}\text { P.I. (will NOT be } \\
\text { handling the animals) }\end{array}$ & $\begin{array}{l}\text { Animal Ethics Lecture } \\
\text { Che }\end{array}$ & Through Hospital \\
\hline Reggie Hamdy & $\begin{array}{l}\text { P.I. (will NOT be } \\
\text { handling the animals) }\end{array}$ & $\begin{array}{l}\text { Animal Ethics Lecture, } \\
\text { online theory course }\end{array}$ & Through Hospital \\
\hline Mia Esser & AHT & Mouse Workshop & Through Hospital \\
\hline Louise Marineau & AHT & Mouse Workshop & Through Hospital \\
\hline Nathalie Guevremont & AHT & Mouse Workshop & Through Hospital \\
\hline Norine Alam & Graduate Student & Mouse Workshop & Through Hospital \\
\hline Fares Hamade & Graduate Student & Mouse Workshop & Through Hospital \\
\hline Maria Kotsiopriftis & Research Assistant & Mouse Workshop & Through Hospital \\
\hline Tasima Haque & Research Assistant & Mouse Workshop & Through Hospital \\
\hline * Indicate for each person, if participating in the local Occupational Health Program, see & \\
http://www.mcgill.ca/research/compliance/animal/occupational/ for details.
\end{tabular}

2. Approval Signatures

Principal Investigator/Course Director

Chair, Facility Animal Care Committee RESEACH ETHTIS OFF.

Chairperson, Ethics Subcommittee (D level or Teaching Protocols Only) Approved Animal Use Period Approved by:

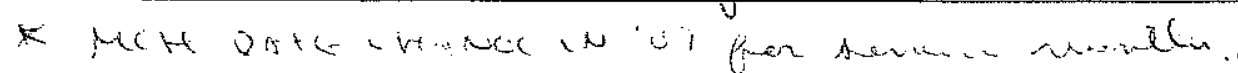

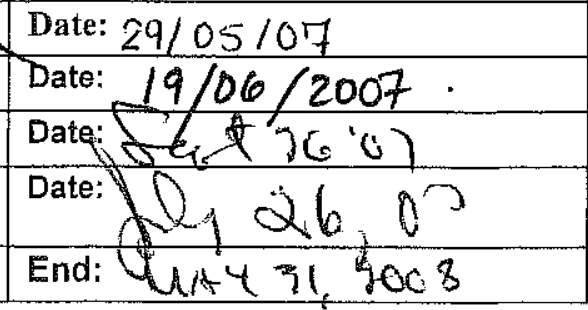


University Animal Care Committee

Ethics Unit

Office of the Vice Principal (Research)

McGill University

James Administration Blde

845 Sherbrooke Street West, room 419

Montreal, Quebec, Canada H3A 2T5
Comité universitaire de protection des animaux

Éthique animale

Bureau de Vice-principal (recherche)

Université McGill

Pavillon James de l'administration

845 , rue Sherbrooke ouest, bureau 419

Montréal, (Québec), Canada H3A 2T5
Tel: (514) 398-2639

Fax :(5I4) 398-4644

www.mcgill.ca/research/compliance/animal/

July 18,2006

The McGill University Animal Care Committee certifies that

Norine Alam has successfully completed a

Mouse Workshop on June 27, 2006.

The training included the following procedures:

$\checkmark$ Handling and restraint

$\checkmark$ Gavage (oral dosing)

$\checkmark$ Injections: subcutaneous, intramuscular, intraperitoneal

$\checkmark$ Blood collection: saphenous and cardiac puncture

$\checkmark$ Determination of anaesthetic depth

$\checkmark$ Euthanasia by cervical dislocation

Certification is valid for 5 years, starting on the date of the workshop.

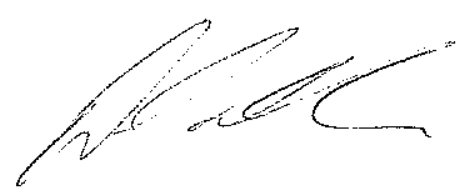

Deanna Collin

Animal Care Training Coordinator, animalcare@mcgill.ca

(Confirmation of training can be obtained by request to the above email address)

Note: Trainee must keep this certificate as other institutions may request it as evidence of training 
University Animal Care Committee

Ethics Unit

Office of the Vice Principal (Research)

McGill University

James Administration Bldg

845 Sherbrooke Street West, room 419

Montreal, Quebec, Canada H3A 2T5
Comité universitaire de protection des animaux

Ethique animale

Bureau de Vice-principal (recherche)

Université McGill

Pavillon James de l'administration

845 , rue Sherbrooke ouest, bureau 419

Montréal, (Québec), Canada H3A 2T5
Tel: (514) 398-2639

Fax :(514) 398-4644

www.mcgill.ca/research/compliance/animal/

July 18,2006

The McGill University Animal Care Committee certifies that

Norine Alam has successfully completed the

Advanced Level

of the

Theory Training Course on Animal Use for

Research and Teaching

on

June 28, 2006.

The training includes the following topics:

- Basic Level: Regulations \& Procedures, Ethics, Basic Animal Care, Occupational Health \& Safety

- Advanced Level: Anesthesia, Analgesia, Euthanasia, Categories, Influencing Factors, and Environmental Enrichment

Please note that this certificate does NOT include practical training, which is obtained by successfully completing an Animal Methodology Workshop where another certificate is issued.

Certification is valid for 5 years, starting on the date indicated above.

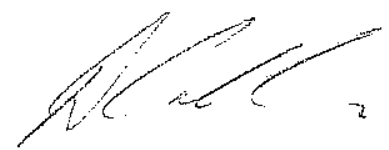

Deanna Collin

Animal Care Training Coordinator, animalcare@mcgill.ca

(Confirmation of training can be obtained by request to the above email address)

Note: Trainee should keep this certificate as other institutions may request it as evidence of training 